\title{
The proprotein convertase subtilisin/kexin type 9 gene E670G polymorphism and serum lipid levels in the Guangxi Bai Ku Yao and Han populations
}

Lynn Htet Htet Aung ${ }^{1}$, Rui-Xing Yin ${ }^{*}$, Lin Miao ${ }^{1}$, Xi-Jiang Hu${ }^{1}$, Ting-Ting Yan ${ }^{1}$, Xiao-Li Cao ${ }^{1}$, Dong-Feng Wu ${ }^{1}$, Qing Li', Shang-Ling Pan', Jin-Zhen $\mathrm{Wu}^{1}$

\begin{abstract}
Background: Proprotein convertase subtilisin-like kexin type 9 (PCSK9) plays a key role in regulating plasma lowdensity lipoprotein cholesterol (LDL-C) levels. However, the association of E670G (rs505151) polymorphism in the PCSK9 gene and serum lipid levels is inconsistent in several previous studies. The present study was undertaken to detect the association of PCSK9 E670G polymorphism and several environmental factors with serum lipid levels in the Guangxi Bai Ku Yao and Han populations.
\end{abstract}

Methods: A total of 649 subjects of Bai Ku Yao and 646 participants of Han were randomly selected from our previous samples. Genotypes of the PCSK9 E670G polymorphism were determined via polymerase chain reaction and restriction fragment length polymorphism combined with gel electrophoresis, and then confirmed by direct sequencing.

Results: Serum levels of total cholesterol, high-density lipoprotein cholesterol (HDL-C), LDL-C, and apolipoprotein (Apo) Al were lower in Bai Ku Yao than in Han $(P<0.01$ for all). The frequency of $G$ allele was $2.00 \%$ in Bai Ku Yao and $4.80 \%$ in $\operatorname{Han}(P<0.01)$. There was significant difference in the genotypic and allelic frequencies between Bai $\mathrm{Ku}$ Yao and Han $(P<0.01)$; between normal LDL-C $(\leq 3.20 \mathrm{mmol} / \mathrm{L})$ and high LDL-C subgroups $(>3.20 \mathrm{mmol} / \mathrm{L}$, $P<0.01)$ in Bai Ku Yao; and between normal HDL-C $(\geq 0.91 \mathrm{mmol} / \mathrm{L})$ and low HDL-C $(<0.91 \mathrm{mmol} / \mathrm{L}, P<0.05)$, between normal ApoAl $(\geq 1.00 \mathrm{~g} / \mathrm{L})$ and low ApoAl $(<1.00 \mathrm{~g} / \mathrm{L}, P<0.05)$, or between normal ApoAl/ApoB ratio $(\geq 1.00)$ and low ApoAl/ApoB ratio $(<1.00, P<0.01)$ subgroups in Han. The $G$ allele carriers in Han had higher serum HDL-C levels and the ratio of ApoAl to ApoB than the $G$ allele noncarriers. The $G$ allele carriers in Han had higher serum HDL-C and ApoAl levels than the $G$ allele noncarriers in males $(P<0.05$ for each), whereas the $G$ allele carriers had lower serum ApoB levels and higher the ratio of ApoAl to ApoB than the $G$ allele noncarriers in females ( $P<0.05$ for all). Serum HDL-C and ApoAl levels in Han were correlated with genotypes $(P<0.05)$ in males, and serum ApoB levels and the ratio of ApoAl to ApoB were associated with genotypes $(P<0.05)$ in females.

Conclusions: The PCSK9 E670G polymorphism is mainly associated with some serum lipid parameters in the Han population. The $\mathrm{G}$ allele carriers had higher serum HDL-C and ApoAl levels in males, and lower serum ApoB levels and higher the ApoAl/ApoB ratio in females than the $G$ allele noncarriers.

\footnotetext{
* Correspondence: yinruixing@yahoo.com.cn

'Department of Cardiology, Institute of Cardiovascular Diseases, the First Affiliated Hospital, Guangxi Medical University, 22 Shuangyong Road,

Nanning 530021, Guangxi, People's Republic of China

Full list of author information is available at the end of the article
} 


\section{Introduction}

Abnormalities in lipid metabolism such as elevated serum levels of total cholesterol (TC) [1], triglyceride (TG) [2], low-density lipoprotein cholesterol (LDL-C) [3], and apolipoprotein (Apo) B [4], or low levels of high-density lipoprotein cholesterol (HDL-C) and ApoAI [4-6] are considered as major risk factors for coronary artery disease (CAD). It is generally agreed that dyslipidemia is complex and the result of the interactions $[7,8]$ of multiple genes [9-11] and multiple environmental factors $[12,13]$. Both family and twin studies have consistently shown that $40-60 \%$ of the interindividual variation in plasma lipid phenotypes is genetic in etiology [14-16]. Although multiple genetic defects have been identified that cause rare Mendelian forms of severe hypercholesterolemia or hypocholesterolemia, the sequence variations in the genome accounting for most of the variation in serum lipid levels in the general population have not been determined.

Proprotein convertase subtilisin-like kexin type 9 (PCSK9, OMIM 607786) is a newly discovered serine protease that plays a key role in LDL-C homeostasis by mediating LDL receptor (LDLR) breakdown through a post-transcriptional mechanism [17-20]. PCSK9 may also regulate $A p o B$-containing lipoprotein production and $A p o B$ secretion $[21,22]$, and promote production of nascent very low-density lipoprotein (VLDL) in the fasting state [23]. Human PCSK9 gene is approximately $22 \mathrm{~kb}$ long, comprising the promoter region and 12 exons, and it is located on chromosome $1 \mathrm{p} 32$. The gene produces a mRNA of $3636 \mathrm{bp}$ encoding a 692-amino acid glycoprotein. This protein, also called neural apoptosis regulated convertase, is a serine protease belonging to the protease $\mathrm{K}$ subfamily of subtilases. It is a subfamily of proteases largely involved in the processing of inactive precursor proteins to the active product and seems to be involved in the inactivation and degradation of LDLR [24-26]. PCSK9 contains a signal sequence and prodomain at its $\mathrm{N}$-terminus, followed by a catalytic domain and cysteine-rich carboxy-terminal domain. PCSK9 undergoes autocatalytic cleavage in the endoplasmic reticulum, releasing the aminoterminal prodomain. The prodomain remains associated with the processed form of PCSK9 as it transits through the secretory pathway. Adenoviral-mediated over-expression of human PCSK9 in mice promotes the accumulation of LDL-C in the plasma but this response is absent in LDLR-deficient animals $[18,20,27]$. Recent studies show that PCSK9 binds directly to the extracellular domain of the LDLR $[28,29]$ and increases its degradation [28]. PCSK9 is expressed most abundantly in the liver, kidney, and small intestine [30]. PCSK9 may enhance degradation of other receptor types or proteins during the development of cerebellum and telencephalon [30] and promote cerebellar cortical neurogenesis, possibly by increased recruitment of undifferentiated neural progenitor cells into the neuronal lineage [31]. The characterization of 'gain-of-function' versus 'loss-of-function' alleles of PCSK9 is based on the phenotype (LDL-C), and not on defined biochemical alterations. Several studies have found that missense mutations increasing the activity of PCSK9 (i.e., gain-of-function mutations) result in an increase of LDL-C levels and CAD [22,32-34] whereas nonsense mutations reducing PCSK9 activity (i.e., loss-of-function mutations) have the opposite effect, lowering LDL-C levels and reducing risk of CAD [35-37]. These findings reveal that PCSK9 activity is a major determinant of plasma levels of LDL-C in humans and make it an attractive therapeutic target for LDL-C lowering. Among the genetic variants of the PCSK9 gene, a common single nucleotide polymorphism (SNP), E670G (rs505151), in exon 12 deserved greater scrutiny, as it was responsible for an amino acid change that could potentially be associated with altered PCSK9 activity. The E670G polymorphism in humans has been found to be associated with modifications of serum LDL-C levels in some studies [38-42] but not in others [37,43-45].

China is a multiethnic country. There are 56 ethnic groups. Han is the largest ethnic group and Yao is the eleventh largest minority among the 55 minority groups according to the population size. There is also an isolated branch of the Yao minority, Bai Ku Yao (Whitetrouser Yao, all of men wear white knee-length knickerbockers). The population size is about 30000 . Because of isolation from the other ethnic groups, the special customs and cultures including their clothing, intra-ethnic marriages, ballad, funeral, bronze drum, spinning top, dietary habits, and corn wine and rum intakes are still completely preserved to the present day. Previous reports by our group have found that several serum lipid phenotypes were lower in Bai Ku Yao than in Han Chinese from the same villages [12,13]. This ethnic difference in serum lipid profiles is still not well known. We hypothesized that some genetic polymorphisms may be different between the two ethnic groups [7-11]. Thus, the aim of this study was to detect the association of PCSK9 E670G polymorphism and several environmental factors with serum lipid phenotypes in the Guangxi Bai $\mathrm{Ku}$ Yao and Han populations.

\section{Materials and methods Study population}

The study population included 649 subjects of Bai $\mathrm{Ku}$ Yao who reside in Lihu and Baxu villages in Nandan County, Guangxi Zhuang Autonomous Region, People's 
Republic of China. They were randomly selected from our previous stratified randomized cluster samples $[12,13]$. The ages of the subjects ranged from 15 to 80 years, with an average age of $35.68 \pm 13.69$ years. There were 324 males (49.92\%) and 325 females (50.08\%). All subjects were rural agricultural workers. The subjects accounted for $2.16 \%$ of total Bai Ku Yao population. During the same period, a total of 646 people of Han Chinese who reside in the same villages were also randomly selected from our previous stratified randomized cluster samples $[12,13]$. The average age of the subjects was $36.59 \pm 17.56$ years (range 15 to 80 ). There were 320 men (49.54\%) and 326 women (50.46\%). All of them were also rural agricultural workers. All study subjects were essentially healthy and had no evidence of any chronic illness, including hepatic, renal, or thyroid. The participants with a history of heart attack or myocardial infarction, stroke, congestive heart failure, diabetes or fasting blood glucose $\geq 7.0 \mathrm{mmol} / \mathrm{L}$ determined by glucose meter were not included. The participants were not taking medications known to affect serum lipid levels (lipid-lowering drugs such as statins or fibrates, beta-blockers, diuretics, or hormones) at the time of sample extraction. The present study was approved by the Ethics Committee of the First Affiliated Hospital, Guangxi Medical University. Informed consent was obtained from all subjects after they received a full explanation of the study.

\section{Epidemiological survey}

The survey was carried out using internationally standardized methods, following a common protocol [46]. Demographic data, socioeconomic status, and lifestyle factors were collected with standardized questionnaires. The alcohol information included questions about the number of liangs (about $50 \mathrm{~g}$ ) of rice wine, corn wine, rum, beer, or liquor consumed during the preceding 12 months. Alcohol consumption was categorized into groups of grams of alcohol per day: $<25$ and $\geq 25$. Smoking status was categorized into groups of cigarettes per day: $<20$ and $\geq 20$. At each examination, weight and height were measured with subjects in light clothing and without shoes. Body weight was measured to the nearest 50 grams, using a portable balance scale. Height was measured to the nearest $0.5 \mathrm{~cm}$ with a portable steel measuring device. Body mass index (BMI) was calculated as the weight in kilograms divided by the square of height in meters. Sitting blood pressure was measured three times with the use of a mercury sphygmomanometer after the subjects had a 5-minute rest, and the average of the three measurements was used for the level of blood pressure. Systolic blood pressure was determined by the first Korotkoff sound, and diastolic blood pressure by the fifth Korotkoff sound.

\section{Biochemical measurements}

Fasting venous blood samples $(8 \mathrm{~mL})$ were obtained from all participants between 8 and 11 AM. A part of the sample $(3 \mathrm{~mL})$ was collected into glass tubes and allowed to clot at room temperature, and used to determine serum lipid levels. Another part of the sample $(5 \mathrm{~mL})$ was transferred to tubes with anticoagulate solution $(4.80 \mathrm{~g} / \mathrm{L}$ citric acid, $14.70 \mathrm{~g} / \mathrm{L}$ glucose, and 13.20 $\mathrm{g} / \mathrm{L}$ tri-sodium citrate) and used to extract DNA. Immediately following clotting serum was separated by centrifugation for 15 minutes at $3000 \mathrm{rpm}$. The levels of TC, TG, HDL-C, and LDL-C in samples were measured using commercial enzymatic reagents, Tcho-1, TG-LH (RANDOX Laboratories Ltd., Ardmore, Diamond Road, Crumlin Co. Antrim, United Kingdom, BT29 4QY), Cholestest N HDL, and Cholestest LDL (Daiichi Pure Chemicals Co., Ltd., Tokyo, Japan); respectively. Serum ApoAI and ApoB levels were detected by the immunoturbidimetric immunoassay using a commercial kit (RANDOX Laboratories Ltd.). All determinations were performed with an autoanalyzer (Type 7170A; Hitachi Ltd., Tokyo, Japan) in the Clinical Science Experiment Center of the First Affiliated Hospital, Guangxi Medical University $[12,13]$.

\section{DNA amplification and genotyping}

Genomic DNA was isolated from peripheral blood leukocytes using the phenol-chloroform method as previously described [7-11]. The extracted DNA was maintained at $4^{\circ} \mathrm{C}$ until analysis. Genotyping of the PCSK9 E670G polymorphism was performed by polymerase chain reaction and restriction fragment length polymorphism (PCR-RFLP). PCR amplification was performed using 5'-CACGGTTGTGTCCCAAATGG-3' and 5'-GAGAGGGACAAGTCGGAACC-3' (Sangon, Shanghai, People's Republic of China) as the forward and reverse primer pairs; respectively. Each amplification reaction was performed using $100 \mathrm{ng}$ of genomic DNA in $25 \mu \mathrm{L}$ of reaction mixture consisting of $25 \mu \mathrm{mol} / \mathrm{L}$ of each primer, $200 \mu \mathrm{mol} / \mathrm{L}$ of each deoxynucleotide triphoisphate, $2.5 \mu \mathrm{L}$ of $10 \times$ PCR buffer $(100 \mathrm{mM}$ Tris$\mathrm{HCl}, \mathrm{pH}$ 8.3, $500 \mathrm{mM} \mathrm{KCl,} 20 \mathrm{mM} \mathrm{MgCl}_{2}, 1 \%$ Triton), and 2 units of Taq polymerase. After initial denaturizing at $94^{\circ} \mathrm{C}$ for $5 \mathrm{~min}$, the reaction mixture was subjected to 35 cycles of $30 \mathrm{~s}$ denaturation at $94^{\circ} \mathrm{C}, 30 \mathrm{~s}$ annealing at $58^{\circ} \mathrm{C}$ and extension $30 \mathrm{~s}$ at $72^{\circ} \mathrm{C}$, followed by a final 5 min extension at $72^{\circ} \mathrm{C}$. After electrophoresis on a $1.2 \%$ agarose gel with $0.5 \mu \mathrm{g} / \mathrm{mL}$ ethidium bromide (EB), the amplification products were visualized under ultraviolet light. Then $2 \mathrm{U}$ of Eam 1104I restriction enzyme was added directly to the PCR products $(10 \mu \mathrm{L})$ and digested at $37^{\circ} \mathrm{C}$ overnight. After restriction enzyme digestion of the amplified DNA, the genotypes were identified by electrophoresis on $2 \%$ agagarose gels and visualized with 
ethidium-bromide staining ultraviolet illumination. Genotypes were scored by an experienced reader blinded to epidemiological data and serum lipid levels. Six samples (AA, AG and GG genotypes in two; respectively) detected by the PCR-RFLP were also confirmed by direct sequencing. The PCR products were purified by low melting point gel electrophoresis and phenol extraction, and then the DNA sequences were analyzed in Shanghai Sangon Biological Engineering Technology \& Services Co., Ltd., People's Republic of China.

\section{Diagnostic criteria}

The normal values of serum TC, TG, HDL-C, LDL-C, ApoAI, ApoB levels, and the ratio of ApoAI to ApoB in our Clinical Science Experiment Center were 3.10-5.17, 0.56-1.70, 0.91-1.81, 2.70-3.20 mmol/L, 1.00-1.78, $0.63-1.14 \mathrm{~g} / \mathrm{L}$, and 1.00-2.50; respectively. The individuals with TC $>5.17 \mathrm{mmol} / \mathrm{L}$ and/or TG $>1.70 \mathrm{mmol} /$ $\mathrm{L}$ were defined as hyperlipidemic $[12,13]$. Hypertension was diagnosed according to the criteria of 1999 World Health Organization-International Society of Hypertension Guidelines for the management of hypertension $[47,48]$. The diagnostic criteria of overweight and obesity were according to the Cooperative Meta-analysis Group of China Obesity Task Force. Normal weight, overweight and obesity were defined as a BMI < 24, 24-28, and $>28 \mathrm{~kg} / \mathrm{m}^{2}$; respectively [49].

\section{Statistical analyses}

Epidemiological data were recorded on a pre-designed form and managed with Excel software. Data analysis was performed using the statistical software package SPSS 13.0 (SPSS Inc., Chicago, Illinois). Quantitative variables were expressed as mean \pm standard deviation (serum TG levels were presented as medians and interquartile ranges). Qualitative variables were expressed as percentages. Allele frequency was determined via direct counting, and the standard goodness-of-fit test was used to test the HardyWeinberg equilibrium. Difference in genotype distribution between the groups was obtained using the chi-square test. The difference in general characteristics between Bai $\mathrm{Ku}$ Yao and Han was tested by the Student's unpaired $t$-test. The association of genotypes and serum lipid parameters was tested by analysis of covariance (ANCOVA). Sex, age, BMI, blood pressure, alcohol consumption, cigarette smoking were adjusted for the statistical analysis. In order to assess the association of serum lipid levels with genotypes $(\mathrm{AA}=1, \mathrm{AG} / \mathrm{GG}=2)$ and several environment factors, multiple linear regression analysis with stepwise modeling was also performed in the combined population of Bai $\mathrm{Ku}$ Yao and Han, Bai Ku Yao, Han, males and females; respectively. A $P$ value of less than 0.05 was considered statistically significant.

\section{Results}

General characteristics and serum lipid levels

The general characteristics and serum lipid levels between the Bai Ku Yao and Han populations are presented in Table 1. The levels of height, weight, systolic blood pressure, pulse pressure, serum TC, HDL-C, LDL-C, ApoAI were lower in Bai Ku Yao than in Han Chinese $(P<0.01-0.001)$, whereas the percentage of subjects who consumed alcohol was higher in Bai Ku Yao than in Han $(P<0.001)$. There were no significant differences in the levels of BMI, diastolic blood pressure, serum TG, ApoB, the ratio of ApoAI to ApoB, age structure, the percentage of subjects who smoked cigarettes, or the ratio of male to female between the two ethnic groups $(P>0.05$ for all).

Table 1 Comparison of demographic, lifestyle characteristics and serum lipid levels between Bai Ku Yao and Han Chinese

\begin{tabular}{|c|c|c|c|c|}
\hline Characteristic & Bai Ku Yao & $\begin{array}{l}\text { Han } \\
\text { Chinese }\end{array}$ & $t\left(\chi^{2}\right)$ & $P$ \\
\hline Number & 649 & 646 & - & - \\
\hline Male/female & $324 / 325$ & $320 / 326$ & 0.139 & 0.889 \\
\hline Age (years) & $\begin{array}{l}35.68 \pm \\
13.69\end{array}$ & $\begin{array}{l}36.59 \pm \\
17.56\end{array}$ & -1.040 & 0.298 \\
\hline Height (cm) & $\begin{array}{l}153.27 \pm \\
7.17\end{array}$ & $\begin{array}{l}156.89 \pm \\
8.83\end{array}$ & -8.356 & 0.000 \\
\hline Weight (kg) & $51.85 \pm 6.99$ & $\begin{array}{l}54.32 \pm \\
10.32\end{array}$ & -5.044 & 0.000 \\
\hline Body mass index $\left(\mathrm{kg} / \mathrm{m}^{2}\right)$ & $22.04 \pm 2.28$ & $22.03 \pm 3.65$ & 0.042 & 0.967 \\
\hline $\begin{array}{l}\text { Systolic blood pressure } \\
(\mathrm{mmHg})\end{array}$ & $\begin{array}{l}116.48 \pm \\
15.78\end{array}$ & $\begin{array}{l}119.54 \pm \\
17.16\end{array}$ & -3.339 & 0.001 \\
\hline $\begin{array}{l}\text { Diastolic blood pressure } \\
(\mathrm{mmHg})\end{array}$ & $74.81 \pm 8.99$ & $\begin{array}{l}75.34 \pm \\
11.10\end{array}$ & -0.936 & 0.350 \\
\hline Pulse pressure (mmHg) & $\begin{array}{l}41.66 \pm \\
11.64\end{array}$ & $44.21 \pm 11.9$ & -3.897 & 0.000 \\
\hline \multicolumn{5}{|l|}{ Cigarette smoking [n (\%)] } \\
\hline Nonsmoker & $442(68.1)$ & $492(76.2)$ & & \\
\hline$<20$ cigarettes/day & $101(15.6)$ & $46(7.1)$ & & \\
\hline$\geq 20$ cigarettes/day & $106(2.3)$ & $108(16.7)$ & 1.468 & 0.142 \\
\hline \multicolumn{5}{|c|}{ Alcohol consumption [n (\%)] } \\
\hline Nondrinker & $383(59.0)$ & $490(75.9)$ & & \\
\hline$<25$ g/day & $186(28.7)$ & $112(17.3)$ & & \\
\hline$\geq 25$ g/day & $74(11.4)$ & $44(6.8)$ & 5.653 & 0.000 \\
\hline Total cholesterol $(\mathrm{mmol} / \mathrm{L})$ & $4.23 \pm 0.93$ & $4.63 \pm 1.07$ & 6.342 & 0.000 \\
\hline Triglyceride (mmol/L) & $0.99(0.66)$ & $1.02(0.74)$ & -1.716 & 0.086 \\
\hline HDL-C (mmol/L) & $1.64 \pm 0.41$ & $1.75 \pm 0.47$ & -4.643 & 0.000 \\
\hline LDL-C (mmol/L) & $2.50 \pm 0.76$ & $2.65 \pm 0.82$ & -3.155 & 0.002 \\
\hline Apolipoprotein (Apo) Al (g/L) & $1.28 \pm 0.32$ & $1.35 \pm 0.31$ & -3.867 & 0.000 \\
\hline ApoB $(g / L)$ & $0.83 \pm 0.21$ & $0.84 \pm 0.24$ & -1.076 & 0.282 \\
\hline ApoAl/ApoB & $1.68 \pm 0.78$ & $1.72 \pm 0.61$ & -0.899 & 0.369 \\
\hline
\end{tabular}

HDL-C, high-density lipoprotein cholesterol; LDL-C, low-density lipoprotein cholesterol. The value of TG was presented as median (interquartile range) The difference between the two ethnic groups was determined by the Wilcoxon-Mann-Whitney test. 


\section{Results of electrophoresis and genotyping}

After the genomic DNA of the samples was amplified by PCR and imaged by $2 \%$ agarose gel electrophoresis, the purpose gene of $440 \mathrm{bp}$ nucleotide sequences could be seen in all samples (Figure 1). The genotypes identified were named according to the presence or absence of the enzyme restriction sites, when an A to $G$ transversion at 670 locus of the PCSK9 gene. The presence of the cutting site indicates the A allele, while its absence indicates the $G$ allele (cannot be cut). Thus, the GG genotype is homozygote for the absence of the site (band at $440 \mathrm{bp}$ ), AG genotype is heterozygote for the absence and presence of the site (bands at 440-, 290and 150-bp), and AA genotype is homozygote for the presence of the site (bands at 290- and 150-bp; Figure 2). The distribution of genotypes of the SNP followed the Hardy-Weinberg equilibrium.

\section{Genotypic and allelic frequencies}

The genotypic and allelic frequencies of E670G polymorphism in the PCSK9 gene are shown in Table 2. The frequency of A and G alleles was $98.00 \%$ and $2.00 \%$ in Bai $\mathrm{Ku}$ Yao, and $95.20 \%$ and $4.80 \%$ in $\operatorname{Han}(P<0.01)$; respectively. The frequency of AA, AG and GG genotypes was $95.99 \%, 4.01 \%$ and $0 \%$ in Bai $\mathrm{Ku} \mathrm{Yao,} \mathrm{and}$ 91.02\%, 8.36\% and $0.62 \%$ in $\operatorname{Han}(P<0.01)$; respectively. There was also significant difference in the genotypic and allelic frequencies between normal LDL-C $(\leq 3.20$ $\mathrm{mmol} / \mathrm{L}$ ) and high LDL-C subgroups (> $3.20 \mathrm{mmol} / \mathrm{L}$, $P<0.01)$ in Bai Ku Yao; and between normal HDL-C

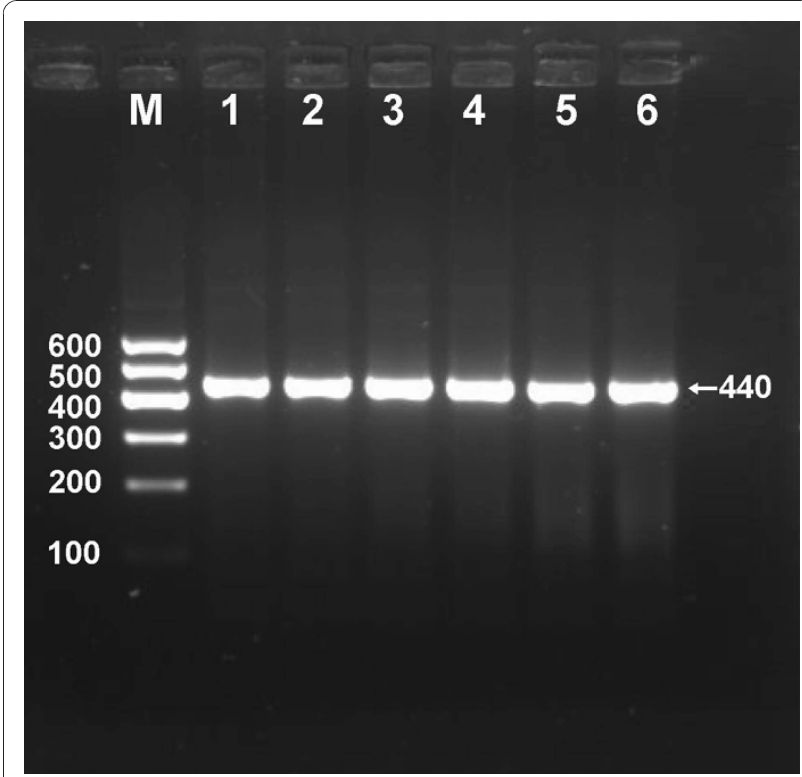

Figure 1 Electrophoresis of PCR products of the samples. Lane M, 100 bp marker ladder; lanes 1-6, samples. The 440 bp bands are the target genes.

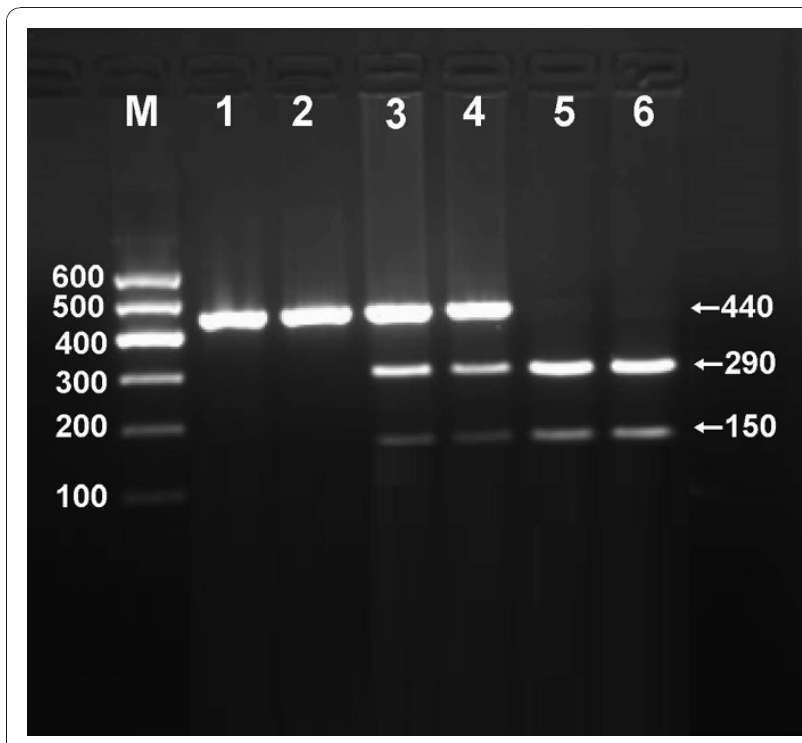

Figure 2 Genotyping of the PCSK9 E670G polymorphism. Lane M, 100 bp marker ladder; lanes 1 and 2, GG genotype (440 bp); lanes 3 and 4, AG genotype (440-, 290- and 150-bp); and lanes 5 and 6, AA genotype (290- and 150-bp).

$(\geq 0.91 \mathrm{mmol} / \mathrm{L})$ and low HDL-C $(<0.91 \mathrm{mmol} / \mathrm{L}, P<$ $0.05)$, between normal ApoAI $(\geq 1.00 \mathrm{~g} / \mathrm{L})$ and low ApoAI $(<1.00 \mathrm{~g} / \mathrm{L}, P<0.05)$, or between normal ApoAI/ApoB ratio $(\geq 1.00)$ and low ApoAI/ApoB ratio $(<1.00, P<0.01)$ subgroups in Han.

\section{Results of sequencing}

The results were shown as AA, AG and GG genotypes by PCR-RFLP, the AA, AG and GG genotypes were also confirmed by sequencing (Figure 3 ); respectively.

\section{Genotypes and serum lipid levels}

As shown in Table 3, the levels of HDL-C and the ratio of ApoAI to ApoB in Han Chinese but not in Bai $\mathrm{Ku}$ Yao were different between the AA and AG/GG genotypes $(P<0.05$ for each). The $\mathrm{G}$ allele carriers had higher serum HDL-C levels and the ratio of ApoAI to ApoB than the $G$ allele noncarriers. When serum lipid parameters in Han were analyzed according to sex, the $G$ allele carriers had higher serum HDL-C and ApoAI levels than the $\mathrm{G}$ allele noncarriers in males $(P<0.05$ for each), whereas the $G$ allele carriers had lower serum ApoB levels and higher the ratio of ApoAI to ApoB than the $\mathrm{G}$ allele noncarriers in females $(P<0.05$ for all).

\section{Relative factors for serum lipid parameters}

Multiple linear regression analysis showed that serum HDL-C levels were correlated with genotypes in Han $(P<0.05)$ but not in Bai Ku Yao (Table 4$)$. When multiple linear regression analysis was performed in the 
Table 2 Comparison of the genotypic and allelic frequencies of PCSK9 E670G polymorphism between Bai Ku Yao and Han Chinese [n (\%)]

\begin{tabular}{|c|c|c|c|c|c|c|}
\hline \multirow[t]{2}{*}{ Group } & \multirow[t]{2}{*}{$\mathrm{n}$} & \multicolumn{3}{|c|}{ Genotype } & \multicolumn{2}{|c|}{ Allele } \\
\hline & & $A A$ & AG & GG & $A$ & G \\
\hline Bai Ku Yao & 649 & $623(95.99)$ & $26(4.01)$ & $0(0.00)$ & $1272(98.00)$ & $26(2.00)$ \\
\hline Han Chinese & 646 & $588(91.02)$ & $54(8.36)$ & $4(0.62)$ & $1230(95.20)$ & $62(4.80)$ \\
\hline$\chi^{2}$ & - & & 14.805 & & & \\
\hline$P$ & - & & 0.001 & & & \\
\hline \multicolumn{7}{|l|}{ Bai Ku Yao } \\
\hline Male & 324 & 309 (95.37) & $15(4.63)$ & $0(0.00)$ & 633 (97.69) & $15(2.31)$ \\
\hline Female & 325 & $314(96.62)$ & $11(3.38)$ & $0(0.00)$ & $639(98.92)$ & $11(1.08)$ \\
\hline$\chi^{2}$ & - & & 0.654 & & \multicolumn{2}{|c|}{0.641} \\
\hline$P$ & - & & 0.419 & & \multicolumn{2}{|c|}{0.423} \\
\hline Normal TC & 549 & $529(96.40)$ & $20(3.60)$ & $0(0.00)$ & $1078(98.18)$ & $20(1.82)$ \\
\hline High TC & 100 & $94(94.00)$ & $6(6.00)$ & $0(0.00)$ & $194(97.00)$ & $6(3.00)$ \\
\hline$\chi^{2}$ & - & & 1.874 & & \multicolumn{2}{|c|}{1.197} \\
\hline$P$ & - & & 0.171 & & \multicolumn{2}{|c|}{0.274} \\
\hline Normal TG & 550 & $526(95.64)$ & $24(4.36)$ & $0(0.00)$ & $1076(97.82)$ & $24(2.18)$ \\
\hline High TG & 99 & 97 (97.98) & $2(2.02)$ & $0(0.00)$ & 196 (98.99) & $2(1.01)$ \\
\hline$\chi^{2}$ & - & & 1.198 & & \multicolumn{2}{|c|}{0.653} \\
\hline$P$ & - & & 0.274 & & \multicolumn{2}{|c|}{0.419} \\
\hline Normal HDL-C & 460 & $444(96.52)$ & $16(3.48)$ & $0(0.00)$ & 904 (92.27) & $16(7.73)$ \\
\hline Low HDL-C & 189 & $179(94.71)$ & $10(5.29)$ & $0(0.00)$ & $368(97.35)$ & $10(2.65)$ \\
\hline$\chi^{2}$ & - & & 1.145 & & \multicolumn{2}{|c|}{1.121} \\
\hline$P$ & - & & 0.285 & & \multicolumn{2}{|c|}{0.290} \\
\hline Normal LDL-C & 488 & 475 (97.34) & $13(2.66)$ & $0(0.00)$ & $963(98.67)$ & $13(1.33)$ \\
\hline High LDL-C & 161 & $148(91.93)$ & $13(8.07)$ & $0(0.00)$ & 309 (95.96) & $13(4.04)$ \\
\hline$\chi^{2}$ & - & & 9.216 & & \multicolumn{2}{|c|}{9.027} \\
\hline$P$ & - & & 0.002 & & \multicolumn{2}{|c|}{0.003} \\
\hline Normal ApoAl & 546 & $523(95.79)$ & $23(4.21)$ & $0(0.00)$ & $1069(97.89)$ & $23(2.11)$ \\
\hline Low ApoAl & 103 & 100 (97.09) & $3(2.91)$ & $0(0.00)$ & $203(98.54)$ & $3(1.46)$ \\
\hline$\chi^{2}$ & - & & 0.118 & & \multicolumn{2}{|c|}{0.115} \\
\hline$P$ & - & & 0.732 & & \multicolumn{2}{|c|}{0.734} \\
\hline Normal ApoB & 605 & $581(95.87)$ & $25(4.13)$ & $0(0.00)$ & $1187(98.10)$ & $25(1.90)$ \\
\hline High ApoB & 43 & $42(97.67)$ & $1(2.33)$ & $0(0.00)$ & $283(98.26)$ & $5(1.74)$ \\
\hline$\chi^{2}$ & - & & 0.338 & & \multicolumn{2}{|c|}{0.331} \\
\hline$P$ & - & & 0.561 & & \multicolumn{2}{|c|}{0.565} \\
\hline NormalApoAl/ApoB & 605 & $583(96.36)$ & $22(3.64)$ & $0(0.00)$ & $1188(98.18)$ & $22(1.82)$ \\
\hline Low ApoAl/ApoB & 92 & $84(91.30)$ & $8(8.70)$ & $0(0.00)$ & $84(95.45)$ & $4(4.55)$ \\
\hline$\chi^{2}$ & - & & 1.913 & & & \\
\hline P & - & & 0.169 & & & \\
\hline \multicolumn{7}{|l|}{ Han Chinese } \\
\hline Male & 320 & $288(90.00)$ & $32(10.00)$ & $0(0.00)$ & $608(95.00)$ & $32(5.00)$ \\
\hline Female & 326 & 300 (92.02) & $22(6.75)$ & $4(1.23)$ & $626(96.01)$ & $26(3.09)$ \\
\hline$\chi^{2}$ & - & & 6.042 & & & \\
\hline$P$ & - & & 0.492 & & & \\
\hline Normal TC & 486 & 442 (90.95) & $40(8.20)$ & $4(0.85)$ & 928 (98.56) & $44(1.44)$ \\
\hline High TC & 160 & $146(91.25)$ & $14(8.75)$ & $0(0.00)$ & 306 (95.63) & $14(4.37)$ \\
\hline$\chi^{2}$ & - & & 1.357 & & & \\
\hline$P$ & - & & 0.507 & & & \\
\hline Normal TG & 530 & $480(90.57)$ & $46(8.68)$ & $4(0.75)$ & $1010(95.28)$ & $50(4.72)$ \\
\hline High TG & 116 & $108(93.11)$ & $8(6.89)$ & $0(0.00)$ & 224 (96.55) & $8(3.45)$ \\
\hline$\chi^{2}$ & - & & 1.305 & & & \\
\hline
\end{tabular}


Table 2 Comparison of the genotypic and allelic frequencies of PCSK9 E670G polymorphism between Bai Ku Yao and Han Chinese [n (\%)] (Continued)

\begin{tabular}{|c|c|c|c|c|c|c|}
\hline$P$ & - & & 0.521 & & \multicolumn{2}{|c|}{0.398} \\
\hline Normal HDL-C & 410 & $366(89.27)$ & $42(10.24)$ & $2(0.49)$ & $776(94.63)$ & $44(4.37)$ \\
\hline Low HDL-C & 236 & $222(94.07)$ & $12(5.08)$ & $2(0.85)$ & $458(97.03)$ & $14(2.97)$ \\
\hline$\chi^{2}$ & & & 4.222 & & \multicolumn{2}{|c|}{4.024} \\
\hline$P$ & - & & 0.039 & & \multicolumn{2}{|c|}{0.045} \\
\hline Normal LDL-C & 458 & $416(90.83)$ & $38(8.30)$ & $4(0.87)$ & $874(95.41)$ & $42(4.59)$ \\
\hline High LDL-C & 188 & $172(91.49)$ & $16(8.51)$ & $0(0.00)$ & $360(95.75)$ & $16(4.25)$ \\
\hline$\chi^{2}$ & - & & 1.656 & & \multicolumn{2}{|c|}{0.068} \\
\hline$P$ & - & & 0.437 & & \multicolumn{2}{|c|}{0.795} \\
\hline Normal ApoAl & 594 & 546 (91.92) & $44(7.41)$ & $4(0.67)$ & $1136(95.62)$ & $52(4.38)$ \\
\hline Low ApoAl & 52 & $42(80.77)$ & $10(19.23)$ & $0(0.00)$ & 92 (90.38) & $10(8.62)$ \\
\hline$\chi^{2}$ & - & & 8.999 & & \multicolumn{2}{|c|}{5.744} \\
\hline$P$ & - & & 0.011 & & \multicolumn{2}{|c|}{0.017} \\
\hline Normal ApoB & 580 & $530(91.38)$ & $46(7.93)$ & $4(0.69)$ & $1060(95.34)$ & $100(4.66)$ \\
\hline High ApoB & 66 & $58(87.88)$ & $8(12.12)$ & $0(0.00)$ & $124(93.94)$ & $8(6.06)$ \\
\hline$\chi^{2}$ & - & & 1.178 & & \multicolumn{2}{|c|}{1.014} \\
\hline$P$ & - & & 0.411 & & \multicolumn{2}{|c|}{0.314} \\
\hline NormalApoAl/ApoB & 624 & $572(91.67)$ & $48(7.67)$ & $4(0.64)$ & $1192(95.51)$ & $56(4.49)$ \\
\hline Low ApoAl/ApoB & 22 & $16(72.73)$ & $6(27.27)$ & $0(0.00)$ & 38 (86.36) & $6(13.64)$ \\
\hline$\chi^{2}$ & - & & 10.725 & & \multicolumn{2}{|c|}{7.787} \\
\hline$P$ & - & & 0.005 & & \multicolumn{2}{|c|}{0.005} \\
\hline
\end{tabular}

Normal TC, TC $\leq 5.17 \mathrm{mmol} / \mathrm{L}$, High TC, TC > $5.17 \mathrm{mmol} / \mathrm{L}$; Normal TG, TG $\leq 1.70 \mathrm{mmol} / \mathrm{L}$, High TG, TG > $1.70 \mathrm{mmol} / \mathrm{L}$; Normal HDL-C, HDL-C $\geq 0.91 \mathrm{mmol} / \mathrm{L}$, Low HDL-C, HDL-C < $0.91 \mathrm{mmol} / \mathrm{L} ;$ Normal LDL-C, LDL-C $\leq 3.20 \mathrm{mmol} / \mathrm{L}$, High LDL-C, LDL-C > $3.20 \mathrm{mmol} / \mathrm{L} ;$ Normal ApoAl, ApoAl $\geq 1.00 \mathrm{~g} / \mathrm{L}$, Low ApoAl, ApoAl < 1.00 g/L; Normal ApoB, ApoB $\leq 1.14 \mathrm{~g} / \mathrm{L}$, High ApoB, ApoB > $1.14 \mathrm{~g} / \mathrm{L} ;$ Normal ApoAl/ApoB, ApoAl/ApoB $\geq 1.00$, Low ApoA1/B, ApoAl/ApoB < 1.00.

males and females in both ethnic groups; respectively, we showed that serum HDL-C and ApoAI levels in Han but not in Bai Ku Yao were correlated with genotypes $(P<0.05)$ in males, and serum ApoB levels and the ratio of ApoAI to ApoB were associated with genotypes $(P<0.05$, Table 5$)$ in females. Serum lipid parameters

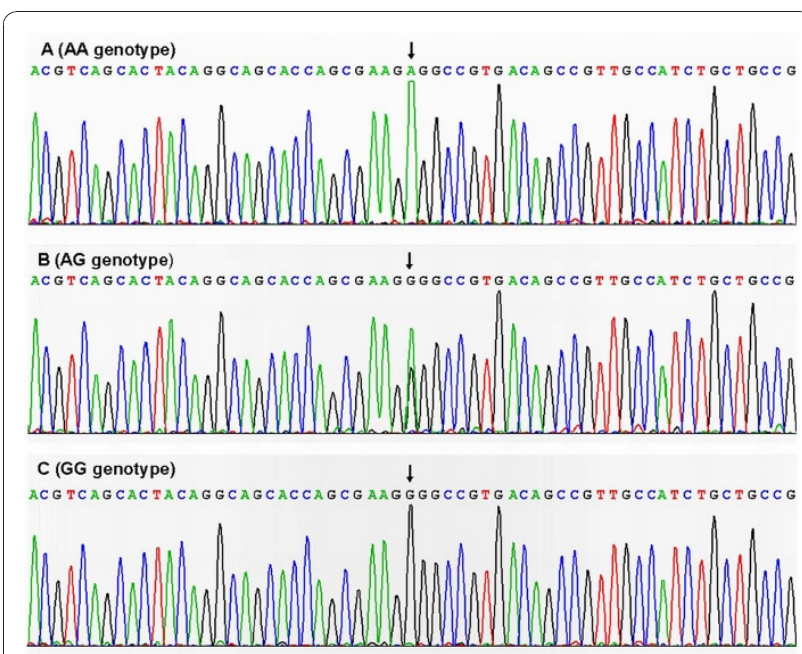

Figure 3 A part of the nucleotide sequence of the PCSK9 E670G polymorphism. (A) AA genotype; (B) AG genotype; (C) GG genotype. were also correlated with sex, age, BMI, alcohol consumption, cigarette smoking, and blood pressure in both ethnic groups $(P<0.05-0.001$, Tables 4 and 5$)$.

\section{Discussion}

We showed that the levels of serum TC, HDL-C, LDL-C and ApoAI were lower in Bai Ku Yao than in Han Chinese. There was no significant difference in the serum levels of TG, ApoB and the ratio of ApoAI to ApoB between the two ethnic groups. It is well known that dyslipidemia is a multifactorial origin, including environmental factors such as demographics, diet, alcohol consumption, cigarette smoking, obesity, exercise, hypertension; genetic factors such as variants in genes coding for proteins; and their interactions [7-13]. Bai Ku Yao is a special and isolated subgroup of the Yao minority in China. Their dietary habits and lifestyle are very special. In addition, strict intra-ethnic marriages have been performed in this ethnic subgroup from time immemorial. Therefore, we believe that some hereditary characteristics and genotypes of lipid metabolism-related genes in this population may be different from those in Han Chinese [9-11].

The frequency spectrum of E670G mutation varied significantly among different races/ethnicities. For example, the frequency of $\mathrm{G}$ allele is rare in whites but present in approximately $24.8 \%$ of blacks [45]. Kotowski 
Table 3 Comparison of serum lipid levels among genotypes of Bai Ku Yao and Han Chinese

\begin{tabular}{|c|c|c|c|c|c|c|c|c|}
\hline Genotype & $\mathbf{n}$ & $\mathrm{TC}(\mathrm{mmol} / \mathrm{L})$ & TG (mmol/L) & $\mathrm{HDL}-\mathrm{C}(\mathrm{mmol} / \mathrm{L})$ & LDL-C (mmol/L) & ApoAl (g/L) & ApoB (g/L) & ApoAl/ApoB \\
\hline \multicolumn{9}{|l|}{ Bai Ku Yao } \\
\hline AA & 623 & $4.27 \pm 0.93$ & $0.98(0.67)$ & $1.62 \pm 0.40$ & $2.51 \pm 0.77$ & $1.28 \pm 0.31$ & $0.83 \pm 0.21$ & $1.66 \pm 0.74$ \\
\hline$A G / G G$ & 26 & $4.34 \pm 1.08$ & $1.04(0.54)$ & $1.60 \pm 0.44$ & $2.58 \pm 0.67$ & $1.24 \pm 0.35$ & $0.83 \pm 0.20$ & $1.59 \pm 0.61$ \\
\hline$F$ & - & 0.679 & 0.089 & 1.327 & 0.583 & 0.042 & 0.252 & 0.279 \\
\hline$P$ & - & 0.410 & 0.642 & 0.250 & 0.445 & 0.839 & 0.616 & 0.597 \\
\hline \multicolumn{9}{|l|}{ Male } \\
\hline $\mathrm{AA}$ & 309 & $4.31 \pm 1.08$ & $1.09(0.79)$ & $1.63 \pm 0.45$ & $2.49 \pm 0.91$ & $1.32 \pm 0.37$ & $0.82 \pm 0.23$ & $1.77 \pm 0.94$ \\
\hline$A G / G G$ & 15 & $4.46 \pm 1.32$ & $1.04(0.62)$ & $1.61 \pm 0.46$ & $2.61 \pm 0.72$ & $1.26 \pm 0.34$ & $0.81 \pm 0.22$ & $1.68 \pm 0.68$ \\
\hline$F$ & - & 0.742 & 0.330 & 0.296 & 0.792 & 0.017 & 0.003 & 0.003 \\
\hline$P$ & - & 0.390 & 0.714 & 0.587 & 0.374 & 0.897 & 0.958 & 0.954 \\
\hline \multicolumn{9}{|l|}{ Female } \\
\hline $\mathrm{AA}$ & 314 & $4.23 \pm 0.76$ & $0.91(0.59)$ & $1.62 \pm 0.35$ & $2.54 \pm 0.79$ & $1.23 \pm 0.24$ & $0.83 \pm 0.19$ & $1.56 \pm 0.47$ \\
\hline$A G / G G$ & 11 & $4.23 \pm 0.86$ & $1.05(0.51)$ & $1.60 \pm 0.44$ & $2.55 \pm 0.90$ & $1.23 \pm 0.38$ & $0.85 \pm 0.18$ & $1.52 \pm 0.56$ \\
\hline$F$ & - & 0.018 & 0.390 & 0.181 & 0.003 & 0.057 & 0.221 & 0.217 \\
\hline$P$ & - & 0.895 & 0.696 & 0.671 & 0.954 & 0.811 & 0.639 & 0.641 \\
\hline \multicolumn{9}{|l|}{ Han Chinese } \\
\hline AA & 588 & $4.61 \pm 1.08$ & $1.01(0.77)$ & $1.74 \pm 0.47$ & $2.63 \pm 0.82$ & $1.35 \pm 0.31$ & $0.84 \pm 0.23$ & $1.70 \pm 0.59$ \\
\hline$A G / G G$ & 58 & $4.79 \pm 0.91$ & $1.10(0.66)$ & $1.86 \pm 0.55$ & $2.74 \pm 0.80$ & $1.41 \pm 0.33$ & $0.83 \pm 0.26$ & $1.87 \pm 0.77$ \\
\hline$F$ & - & 0.607 & 0.089 & 3.959 & 0.332 & 2.165 & 0.650 & 5.394 \\
\hline$P$ & - & 0.436 & 0.929 & 0.047 & 0.565 & 0.142 & 0.420 & 0.021 \\
\hline \multicolumn{9}{|l|}{ Male } \\
\hline $\mathrm{AA}$ & 288 & $4.53 \pm 1.07$ & $1.08(0.90)$ & $1.66 \pm 0.43$ & $2.58 \pm 0.82$ & $1.30 \pm 0.29$ & $0.83 \pm 0.24$ & $1.68 \pm 0.65$ \\
\hline$A G / G G$ & 32 & $5.13 \pm 0.79$ & $1.13(0.80)$ & $1.86 \pm 0.57$ & $2.98 \pm 0.65$ & $1.47 \pm 0.33$ & $0.94 \pm 0.25$ & $1.74 \pm 0.82$ \\
\hline$F$ & - & 2.654 & 0.713 & 4.365 & 2.075 & 4.825 & 1.464 & 0.191 \\
\hline$P$ & - & 0.104 & 0.476 & 0.037 & 0.151 & 0.029 & 0.227 & 0.663 \\
\hline \multicolumn{9}{|l|}{ Female } \\
\hline AA & 300 & $4.69 \pm 1.07$ & $0.96(0.68)$ & $1.82 \pm 0.48$ & $2.71 \pm 0.82$ & $1.39 \pm 0.32$ & $0.85 \pm 0.22$ & $1.72 \pm 0.53$ \\
\hline$A G / G G$ & 26 & $4.51 \pm 0.92$ & $0.97(0.57)$ & $1.87 \pm 0.54$ & $2.56 \pm 0.86$ & $1.36 \pm 0.31$ & $0.74 \pm 0.23$ & $1.97 \pm 0.72$ \\
\hline$F$ & - & 0.138 & 0.190 & 1.235 & 0.178 & 0.130 & 4.412 & 6.655 \\
\hline$P$ & - & 0.710 & 0.850 & 0.267 & 0.674 & 0.719 & 0.036 & 0.010 \\
\hline
\end{tabular}

TC, total cholesterol; TG, triglycerides; HDL-C, high-density lipoprotein cholesterol; LDL-C, low-density lipoprotein cholesterol; ApoAl, apolipoprotein Al; ApoB, apolipoprotein B; ApoAI/ApoB, the ratio of apolipoprotein Al to apolipoprotein B. The value of TG was presented as median (interquartile range). The difference between the genotypes was determined by the Wilcoxon-Mann-Whitney test.

et al. [37] also reported that the minor-allele frequency (670G) in the Dallas Heart Study (DHS) was 3.6\% in whites, $4.2 \%$ in Hispanics, and $26.0 \%$ in blacks. The frequency of the $\mathrm{G}$ allele in patients selected from Universitätsklinikum Hamburg-Eppendorf Martinistrasse, Hamburg, Germany was 5\% (AA 458, AG 45, GG 3) [39] which lies between that observed in the TexGen population, 4.4\% (AA 291, AG 28, GG 0) and that reported for the Lipoprotein Coronary Atherosclerosis Study (LCAS), 7.4\% (AA 324, AG 41, GG 7) by Chen et al. [38] in their original study. There was no statistical significant difference in the frequency of the $G$ allele in patients with LDL-C below the 50th percentile for age and sex, 4.4\% (AA 93, AG 9, GG 0), those with LDL-C between the 50th and 95th percentiles, $6.4 \%$ (AA 160, AG 20, GG 1) and those with LDL-C above the 95th percentile, 6.4\% (AA 205, AG 26, GG 2) [39]. The $670 \mathrm{G}$ carrier in Chinese Taiwanese was identified less frequently in patients with CAD than in controls (9.9\% vs. $11.9 \%)$, but the difference was not significant in a multivariable logistic regression analysis [41]. Two previous studies, however, showed that the $\mathrm{G}$ allele frequency, $3.4 \%$ in healthy U.K. men and patients with clinically defined definite familial hypercholesterolaemia was not associated with any significant effects on plasma lipid levels or CAD risk [43], and 6.0\% in Prospective Study of Pravastatin in the Elderly at Risk (PROSPER) was no significant relationships with baseline LDL-C, response to pravastatin, or vascular disease risk being observed [44]. In the present study, we showed that the frequency of $G$ allele of E670G polymorphism in the PCSK9 gene was lower in Bai Ku Yao (2.00\%) than in Han Chinese (4.80\%). The frequency of AG/GG genotype was also lower in Bai Ku Yao than in Han. There was also significant difference in the genotypic and allelic frequencies between normal and high LDL-C 
Table 4 Correlative factors for serum lipid parameters between Bai Ku Yao and Han Chinese

\begin{tabular}{|c|c|c|c|c|c|c|}
\hline Lipid parameter & Relative factor & Unstandardized coefficient & Std. error & Standardized coefficient & $t$ & $P$ \\
\hline \multicolumn{7}{|l|}{ Bai plus Han } \\
\hline \multirow[t]{5}{*}{$\mathrm{TC}$} & Diastolic blood pressure & 0.020 & 0.003 & 0.205 & 7.026 & 0.000 \\
\hline & Body mass index & 0.060 & 0.009 & 0.190 & 6.812 & 0.000 \\
\hline & Age & 0.108 & 0.017 & 0.180 & 6.544 & 0.000 \\
\hline & Sex & 0.115 & 0.053 & 0.058 & 2.171 & 0.030 \\
\hline & Ethnic group & -0.332 & 0.052 & -0.163 & -6.355 & 0.000 \\
\hline \multirow[t]{4}{*}{ TG } & Body mass index & 0.063 & 0.011 & 0.162 & 5.599 & 0.000 \\
\hline & Sex & -0.236 & 0.073 & -0.097 & -3.208 & 0.001 \\
\hline & Alcohol consumption & 0.146 & 0.047 & 0.094 & 3.129 & 0.002 \\
\hline & Ethnic group & -0.144 & 0.065 & -0.060 & -2.217 & 0.027 \\
\hline \multirow[t]{7}{*}{$\mathrm{HDL}-\mathrm{C}$} & Age & 0.064 & 0.008 & 0.237 & 8.187 & 0.000 \\
\hline & Ethnic group & -0.128 & 0.024 & -0.144 & -5.295 & 0.000 \\
\hline & Body mass index & -0.019 & 0.004 & -0.132 & -4.561 & 0.000 \\
\hline & Sex & 0.137 & 0.027 & 0.155 & 5.101 & 0.000 \\
\hline & Alcohol consumption & 0.077 & 0.017 & 0.136 & 4.463 & 0.000 \\
\hline & Genotype & 0.126 & 0.049 & 0.069 & 2.554 & 0.011 \\
\hline & Diastolic blood pressure & 0.003 & 0.001 & 0.066 & 2.189 & 0.029 \\
\hline \multirow[t]{5}{*}{ LDL-C } & Body mass index & 0.055 & 0.007 & 0.226 & 8.042 & 0.000 \\
\hline & Age & 0.079 & 0.013 & 0.171 & 6.087 & 0.000 \\
\hline & Diastolic blood pressure & 0.011 & 0.002 & 0.149 & 5.138 & 0.000 \\
\hline & Alcohol consumption & -0.132 & 0.026 & -0.136 & -4.978 & 0.000 \\
\hline & Ethnic group & -0.107 & 0.042 & -0.067 & -2.528 & 0.012 \\
\hline \multirow[t]{5}{*}{ ApoAl } & Age & 0.050 & 0.006 & 0.267 & 8.814 & 0.000 \\
\hline & Alcohol consumption & 0.074 & 0.012 & 0.186 & 6.273 & 0.000 \\
\hline & Sex & 0.056 & 0.018 & 0.091 & 3.093 & 0.002 \\
\hline & Ethnic group & -0.078 & 0.017 & 0.123 & -4.651 & 0.000 \\
\hline & Diastolic blood pressure & 0.001 & 0.001 & 0.079 & 2.629 & 0.009 \\
\hline \multirow[t]{3}{*}{ ApoB } & Body mass index & 0.017 & 0.002 & 0.243 & 8.716 & 0.000 \\
\hline & Systolic Blood pressure & 0.004 & 0.001 & 0.176 & 6.041 & 0.000 \\
\hline & Age & 0.020 & 0.004 & 0.148 & 5.392 & 0.000 \\
\hline \multicolumn{7}{|l|}{ Bai Ku Yao } \\
\hline \multirow[t]{3}{*}{$\mathrm{TC}$} & Body mass index & 0.076 & 0.014 & 0.211 & 5.273 & 0.000 \\
\hline & Sex & 0.081 & 0.024 & 0.140 & 3.431 & 0.000 \\
\hline & Systolic blood pressure & 0.008 & 0.004 & 0.088 & 2.139 & 0.033 \\
\hline \multirow[t]{4}{*}{$\mathrm{TG}$} & Sex & -0.478 & 0.118 & -0.211 & -4.060 & 0.001 \\
\hline & Body mass index & 0.069 & 0.020 & 0.141 & 3.498 & 0.001 \\
\hline & Alcohol consumption & 0.176 & 0.063 & 0.133 & 2.816 & 0.005 \\
\hline & Cigarette smoking & -0.179 & 0.073 & -0.128 & -2.455 & 0.014 \\
\hline \multirow[t]{3}{*}{$\mathrm{HDL}-\mathrm{C}$} & Age & 0.052 & 0.011 & 0.192 & 4.622 & 0.000 \\
\hline & Alcohol consumption & 0.077 & 0.022 & 0.169 & 3.580 & 0.000 \\
\hline & Sex & 0.071 & 0.036 & 0.091 & 1.998 & 0.046 \\
\hline \multirow[t]{4}{*}{ LDL-C } & Body mass index & 0.066 & 0.012 & 0.223 & 5.560 & 0.000 \\
\hline & Sex & 0.064 & 0.020 & 0.137 & 3.264 & 0.001 \\
\hline & Alcohol consumption & -0.107 & 0.033 & -0.135 & -3.272 & 0.001 \\
\hline & Diastolic blood pressure & 0.007 & 0.003 & 0.091 & 2.192 & 0.029 \\
\hline \multirow[t]{2}{*}{ ApoAl } & Alcohol consumption & 0.090 & 0.014 & 0.253 & 6.313 & 0.000 \\
\hline & Age & 0.040 & 0.008 & 0.192 & 4.783 & 0.000 \\
\hline \multirow[t]{4}{*}{ ApoB } & Body mass index & 0.019 & 0.004 & 0.217 & 5.374 & 0.000 \\
\hline & Age & 0.017 & 0.006 & 0.117 & 2.772 & 0.006 \\
\hline & Diastolic blood pressure & 0.002 & 0.001 & 0.095 & 2.286 & 0.023 \\
\hline & Alcohol consumption & -0.023 & 0.010 & -0.094 & -2.266 & 0.024 \\
\hline
\end{tabular}


Table 4 Correlative factors for serum lipid parameters between Bai Ku Yao and Han Chinese (Continued)

\begin{tabular}{|c|c|c|c|c|c|c|}
\hline \multirow[t]{3}{*}{ ApoAl/ApoB } & Sex & -0.234 & 0.060 & -0.150 & -3.903 & 0.000 \\
\hline & Body mass index & -0.042 & 0.013 & -0.122 & -3.143 & 0.002 \\
\hline & Age & 0.057 & 0.021 & 0.106 & 2.738 & 0.006 \\
\hline \multicolumn{7}{|l|}{ Han Chinese } \\
\hline \multirow[t]{5}{*}{$\mathrm{TC}$} & Diastolic blood pressure & 0.028 & 0.004 & 0.283 & 7.042 & 0.000 \\
\hline & Age & 0.111 & 0.022 & 0.186 & 4.95 & 0.000 \\
\hline & Body mass index & 0.050 & 0.011 & 0.172 & 4.464 & 0.000 \\
\hline & Sex & 0.354 & 0.088 & 0.165 & 4.022 & 0.000 \\
\hline & Cigarette smoking & 0.110 & 0.053 & 0.086 & 2.082 & 0.038 \\
\hline \multirow[t]{4}{*}{ TG } & Diastolic blood pressure & 0.020 & 0.005 & 0.176 & 4.174 & 0.000 \\
\hline & Body mass index & 0.059 & 0.014 & 0.171 & 4.181 & 0.000 \\
\hline & Cigarette smoking & 0.148 & 0.063 & 0.097 & 2.357 & 0.019 \\
\hline & Alcohol consumption & 0.156 & 0.076 & 0.085 & 2.045 & 0.041 \\
\hline \multirow[t]{6}{*}{$\mathrm{HDL}-\mathrm{C}$} & Age & 0.067 & 0.011 & 0.253 & 6.404 & 0.000 \\
\hline & Sex & 0.216 & 0.038 & 0.226 & 5.605 & 0.000 \\
\hline & Alcohol consumption & 0.104 & 0.028 & 0.151 & 3.746 & 0.000 \\
\hline & Body mass index & -0.024 & 0.005 & -0.187 & -4.586 & 0.000 \\
\hline & Diastolic blood pressure & 0.005 & 0.002 & 0.114 & 2.662 & 0.008 \\
\hline & Genotype & 0.148 & 0.062 & 0.088 & 2.384 & 0.017 \\
\hline \multirow[t]{6}{*}{ LDL-C } & Body mass index & 0.050 & 0.009 & 0.224 & 5.616 & 0.000 \\
\hline & Age & 0.077 & 0.018 & 0.170 & 4.379 & 0.000 \\
\hline & Diastolic blood pressure & 0.015 & 0.003 & 0.200 & 4.813 & 0.000 \\
\hline & Alcohol consumption & -0.128 & 0.048 & -0.108 & -2.67 & 0.008 \\
\hline & Sex & 0.200 & 0.071 & 0.122 & 2.835 & 0.005 \\
\hline & Cigarette smoking & 0.088 & 0.043 & 0.09 & 2.053 & 0.040 \\
\hline \multirow[t]{4}{*}{ ApoAl } & Age & 0.058 & 0.007 & 0.336 & 8.923 & 0.000 \\
\hline & Sex & 0.131 & 0.024 & 0.211 & 5.458 & 0.000 \\
\hline & Alcohol consumption & 0.075 & 0.017 & 0.168 & 4.333 & 0.000 \\
\hline & Diastolic blood pressure & 0.003 & 0.001 & 0.113 & 2.940 & 0.003 \\
\hline \multirow[t]{3}{*}{ ApoB } & Body mass index & 0.016 & 0.002 & 0.247 & 6.400 & 0.000 \\
\hline & Diastolic blood pressure & 0.005 & 0.001 & 0.220 & 5.633 & 0.000 \\
\hline & Age & 0.025 & 0.005 & 0.188 & 5.082 & 0.000 \\
\hline \multirow[t]{2}{*}{ ApoAl/ApoB } & Body mass index & -0.043 & 0.007 & -0.256 & -6.491 & 0.000 \\
\hline & Age & 0.045 & 0.013 & 0.133 & 3.384 & 0.001 \\
\hline
\end{tabular}

TC, total cholesterol; TG, triglyceride; HDL-C, high-density lipoprotein cholesterol; LDL-C, low-density lipoprotein cholesterol; ApoAl, apolipoprotein Al; ApoB, apolipoprotein B.

subgroups in Bai Ku Yao; and between normal and low HDL-C, between normal and low ApoAI, or between normal and low ApoAI/ApoB ratio subgroups in Han. These results indicate that the prevalence of the $G$ allele variation of E670G in the PCSK9 gene may have an ethnic specificity.

The association of E670G polymorphism in the PCSK9 gene and serum lipid levels is still controversial in several previous studies from ethnically diverse populations. Chen et al. [38] have reported that haplotype structure analysis identified E670G as the determinant variant among a black population, exerting a dose effect (GG > EG > EE) and accounting for 3.5\% of plasma LDL-C variability $(F=14.6, P<0.001)$. Plasma TC, $\mathrm{ApoB}$, and lipoprotein (a) levels were also associated with the E670G variant. Distributions of the E670G genotypes in an independent normolipidemic and the hyperlipidemic subjects in the LCAS population were significantly different $(F=7.2, P=0.027)$. Evans and Beil [39] found that the PCSK9 E670G polymorphism in a European population was associated with increased LDL-C in men but not in women. Norata et al. [40] also showed that the $670 \mathrm{G}$ carriers were associated with increased plasma TC, LDL-C, and ApoB levels in the general population. The intima media thickness (IMT) was significantly increased in 670G carriers compared to individuals homozygous for the A allele. The presence of the $670 \mathrm{G}$ allele was also significantly associated with a greater progression of IMT compared to 670AA subjects. Contradictory to these previous results, Hsu et al. 
Table 5 Correlative factors for serum lipid parameters between males and females in both ethnic groups

\begin{tabular}{|c|c|c|c|c|c|c|}
\hline Lipid parameter & Relative factor & Unstandardized coefficient & Std. error & Standardized coefficient & $t$ & $P$ \\
\hline \multicolumn{7}{|l|}{ Bai Ku Yao } \\
\hline \multicolumn{7}{|l|}{ Male } \\
\hline \multirow[t]{2}{*}{$\mathrm{TC}$} & Body mass index & 0.130 & 0.027 & 0.267 & 4.869 & 0.000 \\
\hline & Age & 0.105 & 0.041 & 0.139 & 2.539 & 0.012 \\
\hline TG & Body mass index & 0.128 & 0.036 & 0.197 & 3.516 & 0.001 \\
\hline \multirow[t]{3}{*}{$\mathrm{HDL}-\mathrm{C}$} & Age & 0.064 & 0.018 & 0.204 & 3.563 & 0.000 \\
\hline & Body mass index & -0.031 & 0.011 & -0.155 & -2.870 & 0.004 \\
\hline & Alcohol comsumption & 0.117 & 0.027 & 0.249 & 4.325 & 0.000 \\
\hline$L D L-C$ & Body mass index & 0.111 & 0.022 & 0.276 & 5.022 & 0.000 \\
\hline \multirow[t]{2}{*}{ ApoAl } & Age & 0.047 & 0.014 & 0.185 & 3.281 & 0.001 \\
\hline & Alcohol comsumption & 0.117 & 0.022 & 0.304 & 5.405 & 0.000 \\
\hline ApoB & Body mass index & 0.032 & 0.006 & 0.312 & 5.741 & 0.000 \\
\hline \multirow[t]{3}{*}{ ApoAl/ApoB } & Body mass index & -0.090 & 0.023 & -0.219 & -3.947 & 0.000 \\
\hline & Pulse pressure & 0.009 & 0.004 & 0.113 & 2.044 & 0.042 \\
\hline & Alcohol comsumption & 0.223 & 0.054 & 0.230 & 4.107 & 0.000 \\
\hline \multicolumn{7}{|l|}{ Female } \\
\hline \multirow[t]{2}{*}{$\mathrm{TC}$} & Body mass index & 0.040 & 0.018 & 0.124 & 2.282 & 0.023 \\
\hline & Systolic blood pressure & 0.009 & 0.003 & 0.187 & 3.435 & 0.001 \\
\hline TG & Alcohol comsumption & 0.297 & 0.070 & 0.231 & 4.261 & 0.000 \\
\hline $\mathrm{HDL}-\mathrm{C}$ & Age & 0.045 & 0.013 & 0.183 & 3.340 & 0.001 \\
\hline \multirow[t]{3}{*}{ LDL-C } & Body mass index & 0.032 & 0.014 & 0.126 & 2.327 & 0.021 \\
\hline & Age & 0.050 & 0.025 & 0.119 & 2.034 & 0.043 \\
\hline & Systolic blood pressure & 0.006 & 0.002 & 0.161 & 2.731 & 0.007 \\
\hline ApoAl & Age & 0.038 & 0.009 & 0.217 & 3.988 & 0.000 \\
\hline \multirow[t]{2}{*}{ ApoB } & Body mass index & 0.010 & 0.004 & 0.127 & 2.338 & 0.020 \\
\hline & Systolic blood pressure & 0.002 & 0.001 & 0.202 & 3.716 & 0.000 \\
\hline \multicolumn{7}{|l|}{ Han Chinese } \\
\hline \multicolumn{7}{|l|}{ Male } \\
\hline \multirow[t]{3}{*}{ TC } & Diastolic blood pressure & 0.030 & 0.005 & 0.319 & 5.736 & 0.000 \\
\hline & Body mass index & 0.046 & 0.014 & 0.174 & 3.259 & 0.001 \\
\hline & Age & 0.093 & 0.031 & 0.156 & 2.996 & 0.003 \\
\hline \multirow[t]{3}{*}{$\mathrm{TG}$} & Body mass index & 0.103 & 0.020 & 0.293 & 5.223 & 0.000 \\
\hline & Diastolic blood pressure & 0.016 & 0.007 & 0.127 & 2.230 & 0.026 \\
\hline & Alcohol comsumption & 0.192 & 0.087 & 0.116 & 2.199 & 0.029 \\
\hline \multirow[t]{5}{*}{$\mathrm{HDL}-\mathrm{C}$} & Age & 0.046 & 0.014 & 0.187 & 3.198 & 0.002 \\
\hline & Body mass index & -0.032 & 0.006 & -0.295 & -5.471 & 0.000 \\
\hline & Alcohol comsumption & 0.105 & 0.027 & 0.202 & 3.882 & 0.000 \\
\hline & Systolic blood pressure & 0.005 & 0.002 & 0.176 & 2.947 & 0.003 \\
\hline & Genotype & 0.192 & 0.084 & 0.117 & 2.277 & 0.023 \\
\hline \multirow[t]{2}{*}{ LDL-C } & Diastolic blood pressure & 0.017 & 0.004 & 0.247 & 4.351 & 0.000 \\
\hline & Body mass index & 0.039 & 0.011 & 0.195 & 3.440 & 0.001 \\
\hline \multirow[t]{5}{*}{ ApoAl } & Age & 0.046 & 0.009 & 0.288 & 5.179 & 0.000 \\
\hline & Alcohol comsumption & 0.075 & 0.017 & 0.220 & 4.448 & 0.000 \\
\hline & Systolic blood pressure & 0.004 & 0.001 & 0.209 & 3.682 & 0.000 \\
\hline & Body mass index & -0.011 & 0.004 & -0.156 & -3.030 & 0.003 \\
\hline & Genotype & 0.128 & 0.052 & 0.120 & 2.444 & 0.015 \\
\hline \multirow[t]{2}{*}{ ApoB } & Diastolic blood pressure & 0.006 & 0.001 & 0.279 & 5.154 & 0.000 \\
\hline & Body mass index & 0.017 & 0.003 & 0.278 & 5.141 & 0.000 \\
\hline \multirow[t]{3}{*}{ ApoAl/ApoB } & Body mass index & -0.047 & 0.009 & -0.289 & -5.378 & 0.000 \\
\hline & Pulse pressure & 0.009 & 0.003 & 0.157 & 2.813 & 0.005 \\
\hline & Age & 0.056 & 0.021 & 0.153 & 2.700 & 0.007 \\
\hline
\end{tabular}




\begin{tabular}{|c|c|c|c|c|c|c|}
\hline \multicolumn{7}{|l|}{ Female } \\
\hline \multirow[t]{3}{*}{ TC } & Diastolic blood pressure & 0.025 & 0.006 & 0.234 & 4.267 & 0.000 \\
\hline & Body mass index & 0.056 & 0.019 & 0.168 & 3.018 & 0.003 \\
\hline & Age & 0.115 & 0.032 & 0.195 & 3.623 & 0.000 \\
\hline $\mathrm{TG}$ & Diastolic blood pressure & 0.024 & 0.006 & 0.225 & 4.158 & 0.000 \\
\hline $\mathrm{HDL}-\mathrm{C}$ & Age & 0.071 & 0.015 & 0.263 & 4.906 & 0.000 \\
\hline \multirow[t]{3}{*}{ LDL-C } & Diastolic blood pressure & 0.015 & 0.005 & 0.178 & 3.263 & 0.001 \\
\hline & Body mass index & 0.062 & 0.014 & 0.239 & 4.310 & 0.000 \\
\hline & Age & 0.085 & 0.025 & 0.185 & 3.443 & 0.001 \\
\hline \multirow[t]{2}{*}{ ApoAl } & Age & 0.067 & 0.009 & 0.373 & 7.253 & 0.000 \\
\hline & Alcohol comsumption & 0.106 & 0.052 & 0.105 & 2.042 & 0.042 \\
\hline \multirow[t]{4}{*}{ ApoB } & Diastolic blood pressure & 0.004 & 0.001 & 0.200 & 3.755 & 0.000 \\
\hline & Body mass index & 0.016 & 0.004 & 0.223 & 4.130 & 0.000 \\
\hline & Age & 0.027 & 0.007 & 0.219 & 4.160 & 0.000 \\
\hline & Genotype & -0.075 & 0.037 & -0.099 & -2.036 & 0.043 \\
\hline \multirow[t]{2}{*}{ ApoAl/ApoB } & Body mass index & -0.032 & 0.010 & -0.181 & -3.348 & 0.001 \\
\hline & Genotype & 0.249 & 0.101 & 0.133 & 2.457 & 0.015 \\
\hline
\end{tabular}

TC, total cholesterol; TG, triglyceride; HDL-C, high-density lipoprotein cholesterol; LDL-C, low-density lipoprotein cholesterol; ApoAl, apolipoprotein Al; ApoB, apolipoprotein B.

[41] showed a significantly lower level of LDL-C in 670G carriers in Chinese Taiwanese than in non-carriers $(2.78 \pm 0.82 \mathrm{mmol} / \mathrm{L}$ vs. $3.02 \pm 0.85 \mathrm{mmol} / \mathrm{L} ; P=0.029)$ among 614 unrelated controls, after adjusting for age, gender, smoking, hypertension, diabetes mellitus, BMI, and use of lipid-lowering agents. However, the association between the E670G polymorphism in the PCSK9 gene and plasma LDL-C levels was not confirmed in other studies [37,43-45]. In the present study, we showed that the $\mathrm{G}$ allele carriers in Han but not in Bai $\mathrm{Ku}$ Yao had higher serum HDL-C levels and the ratio of ApoAI to ApoB than the $G$ allele noncarriers. When serum lipid parameters in Han were analyzed according to sex, the $G$ allele carriers had higher serum HDL-C and ApoAI levels than the $G$ allele noncarriers in males, whereas the $G$ allele carriers had lower serum ApoB levels and higher the ratio of ApoAI to ApoB than the $G$ allele noncarriers in females. Multiple linear regression analysis showed that the levels of serum HDL-C and ApoAI in Han were correlated with genotypes in males, and the levels of $A p o B$ and the ratio of ApoAI to ApoB were associated with genotypes in females. Although we showed that the levels of serum LDL-C were slightly higher in the subjects with AG/GG genotype than those with AA genotype, the difference did not reach statistical significance. These results suggest that the PCSK9 E670G polymorphism is mainly associated with some serum lipid parameters in the Han population. The reason for this discrepancy is most likely due to racial and ethnic differences among these studies. The study sample of Evans and Beil was men of European origin, the majority (84\%) of Chen's sample was American whites, and the sample of Huang et al. [45] was restricted to blacks [124/1750 (7\%), because only 3 participants of 1828 whites were found to have this PCSK9 genetic variant. In contrast, our results regarding the E670G polymorphism are restricted to two Chinese populations, Han and Bai Ku Yao. Our study sample is also not different from that of Hsu et al. [41], which included 202 CAD patients and 614 unrelated controls (Chinese Taiwanese).

It is well known that dietary patterns, like the Mediterranean diet, are strongly related with blood lipids levels, as well as with the prevalence and the management of dyslipidemia [50]. We slao showed that serum lipid parameters were correlated with age, sex, alcohol consumption, cigarette smoking, BMI, and blood pressure in this study. These data suggest that the environmental factors also play an important role in determining serum lipid levels in our populations [12,13]. The diet and lifestyle were different between the two ethnic groups. Corn was the staple food and rice, soy, buckwheat, sweet potato, and pumpkin products were the subsidiary foods in Bai $\mathrm{Ku}$ Yao. Approximately 90\% of the beverages were corn wine and rum. The alcohol content is about $15 \%(\mathrm{v} / \mathrm{v})$. They are also accustomed to drink hempseed soup and eat hempseed products. In contrast, rice was the staple food and corn, broomcorn, potato, and taro products were the subsidiary foods in Han. About $90 \%$ of the beverage was rice wine. The content of alcohol is about $30 \%(\mathrm{v} / \mathrm{v})$. The staple and subsidiary foods are more favorable for serum lipid profiles in Bai $\mathrm{Ku}$ Yao than in Han. Corn contains abundant dietary fiber and plant protein [51]. Consumption 
of dietary fiber, specifically the soluble type, such as pectins and guar gum can decrease serum TC levels [52,53]. Levels of total cholesterol (TC) and low-density lipoprotein cholesterol (LDL-C) and the LDL/HDL ratio in subjects with moderate hypercholesterolemia were significantly reduced during a mixture of dietary fiber (guar gum, pectin, soy, pea, corn bran) treatment. The mean percentage reductions from baseline after 51 weeks of treatment were approximately $5 \%$ for TC, $9 \%$ for $\mathrm{LDL}-\mathrm{C}$, and $11 \%$ for the LDL/HDL ratio. There were no significant effects on the levels of either triglycerides or high-density lipoprotein cholesterol (HDL-C) [53]. Plant protein might promote the transportation and excretion of free cholesterol. Dietary soy protein has well-documented beneficial effects on serum lipid concentrations $[54,55]$. Soy protein intake is effective in reducing $\mathrm{TC}$ by $9.3 \%$, LDL-C by $12.9 \%$, and TG by $10.5 \%$ and in increasing HDL-C by $2.4 \%$. Furthermore, the changes in serum TC and LDL-C concentrations were directly related to the initial serum TC concentration [54]. A meta-analyse including 10 studies showed that feeding daily $36 \mathrm{~g}$ soy protein with $52 \mathrm{mg}$ soy-associated isoflavones on average decreased LDL-C by -0.17 $\pm 0.04 \mathrm{mmol} / \mathrm{L}$ and increased HDL-C by $0.03 \pm 0.01$ $\mathrm{mmol} / \mathrm{L}$ [55]. Buckwheat protein product has a potent hypocholesterolemic activity [56,57]. Son et al. [57] found that plasma lipid profiles in rats differed significantly according to grain combination. The levels of TG in the adlay, buckwheat and waxy barley groups were significantly lower than those in the white rice group. The buckwheat and waxy barley groups showed lower levels of TC and LDL-C, and higher HDL-C than the white rice group. Ingestion of $4 \mathrm{~g} /$ day caiapo (the extract of the white-skinned sweet potato Ipomoea batatas) for 6 weeks has been found to reduce plasma TC, LDL-C levels in type 2 diabetic patients previously treated by diet alone [58]. Replacing two thirds of staple food with yam (Dioscorea alata) for 30 days in healthy postmenopausal women can significantly decreased plasma cholesterol concentration by $5.9 \%$, prolonged the lag time of LDL lipoprotein oxidation by $5.8 \%$, and decreased urinary isoprostane levels by $42 \%$ [59]. Adaramoye et al. [60] reported that supplemented diets containing $3 \%$ and $6 \%$ telfairia occidentalis (fluted pumpkin) in rats decreased plasma and postmitochondrial supernatant fraction (PMF) cholesterol levels by $20 \%$ and $30 \%$ and by $30 \%$ and $45 \%$, respectively; decreased the cholesterol-induced increase in plasma and PMF LDL-C levels by $24 \%$ and $48 \%$ and by $28 \%$ and $52 \%$, respectively; and decreased plasma and PMF lipid peroxidation by $24 \%$ and $20 \%$ and by $42 \%$ and $21 \%$, respectively. Dietary hempseed is a rich source of polyunsaturated fatty acids (PUFAs). Hempseed-supplemented diet in animals displayed elevated plasma levels of PUFAs and a prominent enhancement in gamma-linolenic acid levels. When hempseed is added to a cholesterol-enriched diet, cholesterol-induced platelet aggregation returns to control levels $[61,62]$. This normalization may be partly due to increased levels of plasma gamma-linolenic acid [61]. In addition, several experimental and clinical studies have demonstrated that dietary hempseed or hempseed oil can decrease TC, TG and LDL-C levels [63-65], inhibit lipid peroxidation [66], and reduce atherogenic index [67].

\section{Conclusion}

The present study shows that the frequency of $G$ allele of E670G polymorphism in the PCSK9 gene was lower in Bai $\mathrm{Ku}$ Yao than in Han. There was also significant difference in the genotypic and allelic frequencies between normal and high LDL-C subgroups in Bai $\mathrm{Ku}$ Yao; and between normal and low HDL-C, between normal and low ApoAI, or between normal and low ApoAI/ApoB ratio subgroups in Han. The $G$ allele carriers in Han had higher serum HDL-C and ApoAI levels than the $G$ allele noncarriers in males, whereas the $G$ allele carriers had lower serum ApoB levels and higher the ratio of ApoAI to ApoB than the $G$ allele noncarriers in females. Serum HDL-C and ApoAI levels in Han were correlated with genotypes in males, and serum ApoB levels and the ratio of ApoAI to ApoB were associated with genotypes in females. These results suggest that the PCSK9 E670G polymorphism is mainly associated with some serum lipid parameters in the Han population. The $\mathrm{G}$ allele carriers had higher serum HDL-C and ApoAI levels in males, and lower serum $A$ poB levels and higher the ApoAI/ApoB ratio in females than the $\mathrm{G}$ allele noncarriers.

\section{Acknowledgements}

This study was supported by the National Natural Science Foundation of China (No: 30660061)

\section{Author details}

'Department of Cardiology, Institute of Cardiovascular Diseases, the First Affiliated Hospital, Guangxi Medical University, 22 Shuangyong Road, Nanning 530021, Guangxi, People's Republic of China. ${ }^{2}$ Department of Pathophysiology, School of Premedical Sciences, Guangxi Medical University, Nanning 530021, Guangxi, People's Republic of China.

\section{Authors' contributions}

LHHA participated in the design, undertook genotyping, and helped to draft the manuscript. RXY conceived the study, participated in the design, carried out the epidemiological survey, collected the samples, and drafted the manuscript. LM, XJH, TTY, XLC, DFW, and QL collaborated to the genotyping. SLP and JZW carried out the epidemiological survey, collected the samples, and helped to carry out the genotyping. All authors read and approved the final manuscript.

\section{Competing interests}

The authors declare that they have no competing interests. 
Received: 23 December 2010 Accepted: 13 January 2011

Published: 13 January 2011

\section{References}

1. Martin MJ, Hulley SB, Browner WS, Kuller LH, Wentworth D: Serum cholesterol, blood pressure and mortality: implications from a cohort of 361,662 men. Lancet 1986, 2:933-6.

2. Davignon J, Cohn JS: Triglycerides: a risk factor for coronary heart disease. Atherosclerosis 1996, 124:S57-S64.

3. März W, Scharnagl H, Winkler K, Tiran A, Nauck M, Boehm BO, Winkelmann BR: Low-density lipoprotein triglycerides associated with low-grade systemic inflammation, adhesion molecules, and angiographic coronary artery disease: the Ludwigshafen Risk and Cardiovascular Health study. Circulation 2004, 110:3068-74.

4. Kwiterovich PO Jr, Coresh J, Smith HH, Bachorik PS, Derby CA, Pearson TA: Comparison of the plasma levels of apolipoproteins $B$ and $A-1$, and other risk factors in men and women with premature coronary artery disease. Am J Cardiol 1992, 69:1015-21.

5. Durrington PN, Hunt L, Ishola M, Kane J, Stephens WP: Serum apolipoproteins $\mathrm{Al}$ and $\mathrm{B}$ and lipoproteins in middle aged men with and without previous myocardial infarction. Br Heart J 1986, 56:206-12.

6. Boden WE: High-density lipoprotein cholesterol as an independent risk factor in cardiovascular disease: Assessing the data from Framingham to the Veterans Affairs High-Density Lipoprotein Intervention Trail. Am J Cardiol 2000, 86:19L-22L.

7. Zhou Y, Yin R, Deng Y, Li Y, Wu J: Interactions between alcohol intake and the polymorphism of rs708272 on serum high-density lipoprotein cholesterol levels in the Guangxi Hei Yi Zhuang population. Alcohol 2008, 42:583-91.

8. Ruixing $Y$, Yiyang $L$, Meng $L$, Kela $L$, Xingjiang $L$, Lin $Z$, Wanying $L$, Jinzhen W, Dezhai $Y$, Weixiong L: Interactions of the apolipoprotein C-III $3238 \mathrm{C}>\mathrm{G}$ polymorphism and alcohol consumption on serum triglyceride levels. Lipids Health Dis 2010, 9:86.

9. Meng $L$, Ruixing $Y$, Yiyang $L$, Xingjiang $L$, Kela $L$, Wanying $L$, Lin $Z$, Weixiong L, Dezhai Y, Shangling P: Association of LIPC -250G > A polymorphism and several environmental factors with serum lipid levels in the Guangxi Bai Ku Yao and Han populations. Lipids Health Dis 2010, 9:28.

10. Liu WY, Yin RX, Zhang L, Cao XL, Miao L, Wu DF, Aung LH, Hu XJ, Lin WX, Yang DZ: Association of the LIPG 584C > T polymorphism and serum lipid levels in the Guangxi Bai Ku Yao and Han populations. Lipids Health Dis 2010, 9:110.

11. Zhang L, Yin RX, Liu WY, Miao L, Wu DF, Aung LH, Hu XJ, Cao XL, Wu JZ, Pan SL: Association of methylenetetrahydrofolate reductase C677T polymorphism and serum lipid levels in the Guangxi Bai Ku Yao and Han populations. Lipids Health Dis 2010, 9:123

12. Ruixing $Y$, Qiming F, Dezhai $Y$, Shuquan $L$, Weixiong $L$, Shangling $P$, Hai W, Yongzhong $\mathrm{Y}$, Feng $\mathrm{H}$, Shuming $\mathrm{Q}$ : Comparison of demography, diet, lifestyle, and serum lipid levels between the Guangxi Bai Ku Yao and Han populations. J Lipid Res 2007, 48:2673-81.

13. Ruixing Y, Dezhai Y, Shuquan L, Yuming C, Hanjun Y, Qiming F, Shangling $P$, Weixiong $L$, Jing $T$, Yiyang L: Hyperlipidaemia and its risk factors in the Guangxi Bai Ku Yao and Han populations. Public Health Nutr 2009, 12:816-24

14. Heller DA, de Faire U, Pedersen NL, Dahlén G, McClearn GE: Genetic and environmental influences on serum lipid levels in twins. $N$ Engl J Med 1993, 328:1150-6.

15. Steinmetz J, Boerwinkle E, Gueguen R, Visvikis S, Henny J, Siest G: Multivariate genetic analysis of high density lipoprotein particles. Atherosclerosis 1992, 92:219-27.

16. Pérusse L, Rice T, Després JP, Bergeron J, Province MA, Gagnon J, Leon AS, Rao DC, Skinner JS, Wilmore JH, Bouchard C: Familial resemblance of plasma lipids, lipoproteins and postheparin lipoprotein and hepatic lipases in the HERITAGE Family Study. Arterioscler Thromb Vasc Biol 1997, 17:3263-9.

17. Maxwell KN, Breslow JL: Adenoviral-mediated expression of PCSK9 in mice results in a low-density lipoprotein receptor knockout phenotype. Proc Natl Acad Sci USA 2004, 101:7100-5.

18. Park SW, Moon YA, Horton JD: Post-transcriptional regulation of low density lipoprotein receptor protein by proprotein convertase subtilisin/ kexin type 9a in mouse liver. J Biol Chem 2004, 279:50630-8.
19. Benjannet $S$, Rhainds D, Essalmani R, Mayne J, Wickham L, Jin W, Asselin MC, Hamelin J, Varret M, Allard D, Trillard M, Abifadel M, Tebon A, Attie AD, Rader DJ, Boileau C, Brissette L, Chrétien M, Prat A, Seidah NG: NARC-1/PCSK9 and its natural mutants: zymogen cleavage and effects on the low density lipoprotein (LDL) receptor and LDL cholesterol. J Biol Chem 2004, 279:48865-75.

20. Lalanne F, Lambert G, Amar MJ, Chetiveaux M, Zair Y, Jarnoux AL, Ouguerram K, Friburg J, Seidah NG, Brewer HB Jr, Krempf M, Costet P: Wildtype PCSK9 inhibits LDL clearance but does not affect apoB-containing lipoprotein production in mouse and cultured cells. J Lipid Res 2005, 46:1312-9.

21. Ouguerram K, Chetiveaux M, Zair $Y$, Costet $P$, Abifadel M, Varret $M$, Boileau C, Magot T, Krempf M: Apolipoprotein B100 metabolism in autosomal-dominant hypercholesterolemia related to mutations in PCSK9. Arterioscler Thromb Vasc Biol 2004, 24:1448-53.

22. Sun XM, Eden ER, Tosi I, Neuwirth CK, Wile D, Naoumova RP, Soutar AK: Evidence for effect of mutant PCSK9 on apolipoprotein B secretion as the cause of unusually severe dominant hypercholesterolaemia. Hum Mol Genet 2005, 14:1161-9.

23. Lambert G, Jarnoux AL, Pineau T, Pape O, Chetiveaux M, Laboisse C, Krempf $M$, Costet $P$ : Fasting induces hyperlipidemia in mice overexpressing proprotein convertase subtilisin kexin type 9: lack of modulation of very-low-density lipoprotein hepatic output by the lowdensity lipoprotein receptor. Endocrinology 2006, 147:4985-95.

24. Zhou A, Webb G, Zhu X, Steiner DF: Proteolytic processing in the secretory pathway. J Biol Chem 1999, 274:20745-8.

25. Maxwell KN, Fisher EA, Breslow JL: Overexpression of PCSK9 accelerates the degradation of the LDLR in a post-endoplasmic reticulum compartment. Proc Natl Acad Sci USA 2005, 102:2069-74.

26. Poirier S, Mayer G, Benjannet S, Bergeron E, Marcinkiewicz J, Nassoury N, Mayer H, Nimpf J, Prat A, Seidah NG: The proprotein convertase PCSK9 induces the degradation of LDLR and its closest family members VLDLR and APOER2. J Biol Chem 2008, 283:2363-72.

27. Maxwell KN, Breslow JL: Proprotein convertase subtilisin kexin 9: the third locus implicated in autosomal dominant hypercholesterolemia. Curr Opin Lipidol 2005, 16:167-72.

28. Zhang DW, Lagace TA, Garuti R, Zhao Z, McDonald M, Horton JD, Cohen JC, Hobbs HH: Binding of PCSK9 to EGFA repeat of LDL receptor decreases receptor recycling and increases degradation. $J$ Biol Chem 2007, 282:18602-12.

29. Cunningham D, Danley DE, Geoghegan KF, Griffor MC, Hawkins JL, Subashi TA, Varghese AH, Ammirati MJ, Culp JS, Hoth LR, Mansour MN, McGrath KM, Seddon AP, Shenolikar S, Stutzman-Engwall KJ, Warren LC, Xia D, Qiu X: Structural and biophysical studies of PCSK9 and its mutants linked to familial hypercholesterolemia. Nat Struct Mol Biol 2007, 14:413-9.

30. Seidah NG, Benjannet S, Wickham L, Marcinkiewicz J, Jasmin SB, Stifani S, Basak A, Prat A, Chretien M: The secretory proprotein convertase neural apoptosis-regulated convertase 1 (NARC-1): liver regeneration and neuronal differentiation. Proc Natl Acad Sci USA 2003, 100:928-33.

31. Seidah NG, Benjannet S, Wickham L, Marcinkiewicz J, Jasmin SB, Stifani S, Basak A, Prat A, Chretien M: The secretory proprotein convertase neural apoptosis-regulated convertase 1 (NARC-1): liver regeneration and neuronal differentiation. Proc Natl Acad Sci USA 2003, 100:928-33.

32. Abifadel $M$, Varret $M$, Rabès JP, Allard D, Ouquerram K, Devillers $M$, Cruaud C, Benjannet S, Wickham L, Erlich D, Derré A, Villéger L, Farnier M, Beucler I, Bruckert E, Chambaz J, Chanu B, Lecerf JM, Luc G, Moulin P, Weissenbach J, Prat A, Krempf M, Junien C, Seidah NG, Boileau C: Mutations in PCSK9 cause autosomal dominant hypercholesterolemia. Nat Genet 2003, 34:154-6.

33. Timms KM, Wagner S, Samuels ME, Forbey K, Goldfine H, Jammulapati S, Skolnick MH, Hopkins PN, Hunt SC, Shattuck DM: A mutation in PCSK9 causing autosomal-dominant hypercholesterolemia in a Utah pedigree. Hum Genet 2004, 114:349-53.

34. Leren TP: Mutations in the PCSK9 gene in Norwegian subjects with autosomal dominant hypercholesterolemia. Clin Genet 2004, 65:419-22.

35. Cohen JC, Boerwinkle E, Mosley TH Jr, Hobbs HH: Sequence variations in PCSK9, low LDL, and protection against coronary heart disease. $N$ Engl J Med 2006, 354:1264-72.

36. Cohen J, Pertsemlidis A, Kotowski IK, Graham R, Garcia CK, Hobbs HH: Low $\mathrm{LDL}$ cholesterol in individuals of African descent resulting from frequent nonsense mutations in PCSK9. Nat Genet 2005, 37:161-5. 
37. Kotowski IK, Pertsemlidis A, Luke A, Cooper RS, Vega GL, Cohen JC, Hobbs HH: A spectrum of PCSK9 alleles contributes to plasma levels of low-density lipoprotein cholesterol. Am J Hum Genet 2006, 78:410-22.

38. Chen SN, Ballantyne CM, Gotto AM Jr, Tan Y, Willerson JT, Marian AJ: A common PCSK9 haplotype, encompassing the E670G coding single nucleotide polymorphism, is a novel genetic marker for plasma lowdensity lipoprotein cholesterol levels and severity of coronary atherosclerosis. J Am Coll Cardiol 2005, 45:1611-9.

39. Evans D, Beil FU: The E670G SNP in the PCSK9 gene is associated with polygenic hypercholesterolemia in men but not in women. BMC Med Genet 2006, 7:66.

40. Norata GD, Garlaschelli K, Grigore L, Raselli S, Tramontana S, Meneghetti F, Artali $R$, Noto $D$, Cefalù $A B$, Buccianti $G$, Averna M, Catapano $A L$ : Effects of PCSK9 variants on common carotid artery intima media thickness and relation to ApoE alleles. Atherosclerosis 2010, 208:177-82.

41. Hsu LA, Teng MS, Ko YL, Chang CJ, Wu S, Wang CL, Hu CF: The PCSK9 gene E670G polymorphism affects low-density lipoprotein cholesterol levels but is not a risk factor for coronary artery disease in ethnic Chinese in Taiwan. Clin Chem Lab Med 2009, 47:154-8.

42. Ding K, Kullo IJ: Molecular population genetics of PCSK9: a signature of recent positive selection. Pharmacogenet Genomics 2008, 18:169-79.

43. Scartezini M, Hubbart C, Whittall RA, Cooper JA, Neil AH, Humphries SE: The PCSK9 gene R46L variant is associated with lower plasma lipid levels and cardiovascular risk in healthy U.K. men. Clin Sci (Lond) 2007, 113:435-41.

44. Polisecki E, Peter I, Robertson M, McMahon AD, Ford I, Packard C, Shepherd J, Jukema JW, Blauw GJ, Westendorp RG, de Craen AJ, Trompet S, Buckley BM, Murphy MB, Ordovas JM, Schaefer EJ, PROSPER Study Group: Genetic variation at the PCSK9 locus moderately lowers low-density lipoprotein cholesterol levels, but does not significantly lower vascular disease risk in an elderly population. Atherosclerosis 2008, 200:95-101.

45. Huang CC, Fornage M, Lloyd-Jones DM, Wei GS, Boerwinkle E, Liu K Longitudinal association of PCSK9 sequence variations with low-density lipoprotein cholesterol levels: the Coronary Artery Risk Development in Young Adults Study. Circ Cardiovasc Genet 2009, 2:354-61.

46. People's Republic of China-United States Cardiovascular and Cardiopulmonary Epidemiology Research Group: An epidemiological study of cardiovascular and cardiopulmonary disease risk factors in four populations in the People's Republic of China. Baseline report from the P.R.C.-U.S.A. Collaborative Study. Circulation 1992, 85:1083-96.

47. Ruixing $Y$, Weixiong $L$, Hanjun $Y$, Dezhai $Y$, Shuquan $L$, Shangling $P$, Qiming F, Jinzhen W, Jianting G, Yaju D: Diet, lifestyle, and blood pressure of the middle-aged and elderly in the Guangxi Bai Ku Yao and Han populations. Am J Hypertens 2008, 21:382-7.

48. Ruixing $Y$, Shangling P, Shuquan L, Dezhai $Y$, Weixiong L, Qiming F, Yuming C, Yaoheng H, Yijiang Z, Qinchen L: Comparison of hypertension and its risk factors between the Guangxi Bai Ku Yao and Han populations. Blood Press 2008, 17:306-16.

49. Cooperative Meta-analysis Group of China Obesity Task Force: Predictive values of body mass index and waist circumference to risk factors of related diseases in Chinese adult population. Chin J Epidemiol 2002, 23:5-10.

50. de Lorgeril M, Salen P, Martin JL, Monjaud I, Delaye J, Mamelle N: Mediterranean diet, traditional risk factors and the rate of cardiovascular complications after myocardial infarction. Final report of the Lyon Diet Heart Study. Circulation 1999, 99:779-85.

51. Dong W, Ma X, Zhang D, Yu S: Effect of maize embryo on delaying aging. Food Sci 2002, 23:95-7.

52. Lairon D: Dietary fibres: effects on lipid metabolism and mechanisms of action. Eur J Clin Nutr 1996, 50:125-33.

53. Hunninghake DB, Miller VT, LaRosa JC, Kinosian B, Jacobson T, Brown V, Howard WJ, Edelman DA, O'Connor RR: Long-term treatment of hypercholesterolemia with dietary fiber. Am J Med 1994, 97:504-8.

54. Anderson JW, Johnstone BM, Cook-Newell ME: Meta-analysis of the effects of soy protein intake on serum lipids. N Engl J Med 1995, 333:276-82.

55. Weggemans RM, Trautwein EA: Relation between soy-associated isoflavones and LDL and HDL cholesterol concentrations in humans: a meta-analysis. Eur J Clin Nutr 2003, 57:940-6.

56. Tomotake H, Shimaoka I, Kayashita J, Yokoyama F, Nakajoh M, Kato N: Stronger suppression of plasma cholesterol and enhancement of the fecal excretion of steroids by a buckwheat protein product than by a soy protein isolate in rats fed on a cholesterol-free diet. Biosci Biotechnol Biochem 2001, 65:1412-4.

57. Son BK, Kim JY, Lee SS: Effect of adlay, buckwheat and barley on lipid metabolism and aorta histopathology in rats fed an obesogenic diet. Ann Nutr Metab 2008, 52:181-7.

58. Ludvik BH, Mahdjoobian K, Waldhaeusl W, Hofer A, Prager R, KautzkyWiller A, Pacini G: The effect of Ipomoea batatas (Caiapo) on glucose metabolism and serum cholesterol in patients with type 2 diabetes: a randomized study. Diabetes Care 2002, 25:239-40.

59. Wu WH, Liu LY, Chung CJ, Jou HJ, Wang TA: Estrogenic effect of yam ingestion in healthy postmenopausal women. J Am Coll Nutr 2005, 24:235-43

60. Adaramoye OA, Achem J, Akintayo OO, Fafunso MA: Hypolipidemic effect of Telfairia occidentalis (fluted pumpkin) in rats fed a cholesterol-rich diet. J Med Food 2007, 10:330-6.

61. Prociuk MA, Edel AL, Richard MN, Gavel NT, Ander BP, Dupasquier CM, Pierce GN: Cholesterol-induced stimulation of platelet aggregation is prevented by a hempseed-enriched diet. Can J Physiol Pharmacol 2008, 86:153-9.

62. Richard MN, Ganguly R, Steigerwald SN, Al-Khalifa A, Pierce GN: Dietary hempseed reduces platelet aggregation. J Thromb Haemost 2007, 5:424-5.

63. Cen L, Qin W, Ye Y: Effect of Canabis Sativa $L$ on serum cholesterol level in rats. J Guangxi Med Univ 1984, 1:20-2.

64. Qin W, Cen L, Ye Y: The effect of some foods on serum cholesterol level in rats. Acta Nutrimenta Sinica 1986, 8:136-40.

65. Schwab US, Callaway J, Erkkila AT, Gynther J, Uusitupa MI, Jarvinen T: Effects of hempseed and flaxseed oils on the profile of serum lipids, serum total and lipoprotein lipid concentrations and haemostatic factors. Eur J Nutr 2006, 45:470-7.

66. Ren HY, Sun HG, Ma JZ, Zhang Y, Yi CR, Wu MX, Liu WL, Li GL: Experimental study on the effects of hemp fruit oil on serun lipid levels and lipid peroxidation. Chin J Tradit Med Sci Technol 1997, 4:200.

67. Ren HY, Sun HG, Zhang Y, Yi CR, Wu MX, Li GL, Liu WL: Lipid-lowering and antiatherosclerotic effects of hemp fruit oil in partridges. Henan Tradit Chin Med 1998, 18:294-5.

doi:10.1186/1476-511X-10-5

Cite this article as: Aung et al:: The proprotein convertase subtilisin/ kexin type 9 gene E670G polymorphism and serum lipid levels in the Guangxi Bai Ku Yao and Han populations. Lipids in Health and Disease 2011 10:5.

\section{Submit your next manuscript to BioMed Central and take full advantage of:}

- Convenient online submission

- Thorough peer review

- No space constraints or color figure charges

- Immediate publication on acceptance

- Inclusion in PubMed, CAS, Scopus and Google Scholar

- Research which is freely available for redistribution

Submit your manuscript at www.biomedcentral.com/submit
C Biomed Central 